US Army Corps of Engineers ${ }_{\circledast}$

Engineer Research and

Development Center

Navigation Systems Research Program

Practical Resilience Metrics for Coastal Infrastructure Features

Bilal M. Ayyub

May 2019

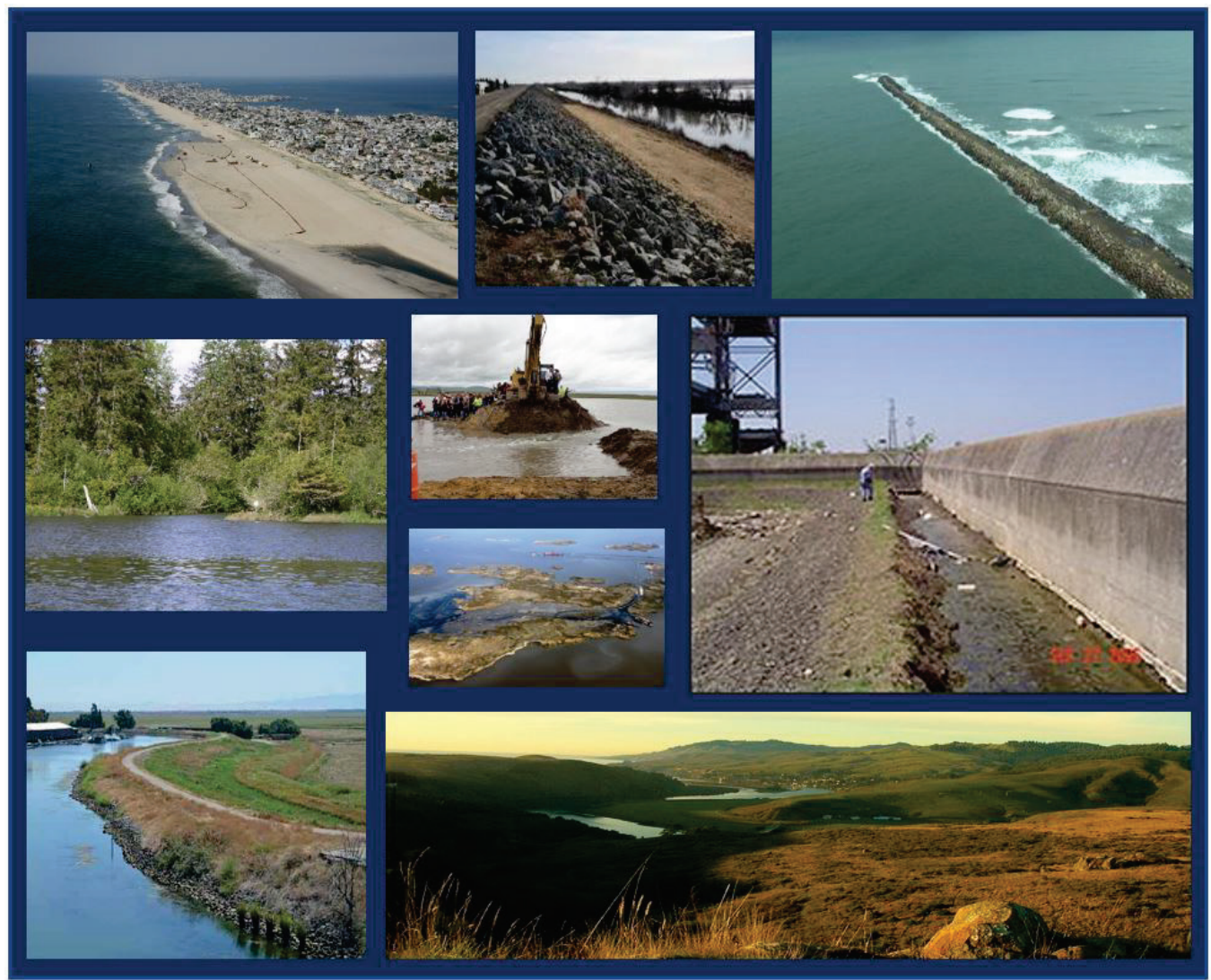


The U.S. Army Engineer Research and Development Center (ERDC) solves the nation's toughest engineering and environmental challenges. ERDC develops innovative solutions in civil and military engineering, geospatial sciences, water resources, and environmental sciences for the Army, the Department of Defense, civilian agencies, and our nation's public good. Find out more at www.erdc.usace.army.mil.

To search for other technical reports published by ERDC, visit the ERDC online library at http://acwc.sdp.sirsi.net/client/default. 
May 2019

\title{
Practical Resilience Metrics for Coastal Infrastructure Features
}

Bilal M. Ayyub

BMA Engineering, Inc. (BMA)

11429 Palatine Drive

Potomac, MD 20854

Final report

Approved for public release; distribution is unlimited.

\author{
Prepared for U.S. Army Corps of Engineers \\ Washington, DC 20314-1000 \\ Under Project 454623, "Tools and Metrics for Coastal Resilience" \\ Monitored by Coastal and Hydraulics Laboratory \\ U.S. Army Engineer Research and Development Center \\ 3909 Halls Ferry Road \\ Vicksburg, MS 39180-6199
}




\section{Abstract}

This effort is directed towards improving basic understanding of the resilience of complex systems for the development of practical resilience metrics that quantify the capacity to withstand damages, rapidly recover, and adapt to future change. The resilience metrics are based on practical performance measures of coastal infrastructure.

Massive savings could be realized by enhancing the resilience of a system, including infrastructure, networks, and communities through risk reduction and expeditious recovery. Existing metrics do not always lend themselves easily and intuitively to practical applications in effective and efficient manners. The coastal and storm damage reduction, navigation, and environmental missions of the U.S. Army Corps of Engineers (USACE) require consistent, transparent, quantitative metrics with which to understand the resiliency of these complex systems.

This report provides a resilience definition that meets a set of requirements with clear relationships to metrics of the relevant abstract notions of reliability and risk. The report also provides metrics that are practical and simplified while capturing all the attribute set in the resilience definition. Recovery models with case studies, and illustrative examples, are also provided. Next steps are defined. The report contributes towards advancing the USACE capabilities in defining, quantifying, and assessing coastal and watershed system resilience.

DISCLAIMER: The contents of this report are not to be used for advertising, publication, or promotional purposes. Citation of trade names does not constitute an official endorsement or approval of the use of such commercial products. All product names and trademarks cited are the property of their respective owners. The findings of this report are not to be construed as an official Department of the Army position unless so designated by other authorized documents.

DESTROY THIS REPORT WHEN NO LONGER NEEDED. DO NOT RETURN IT TO THE ORIGINATOR. 


\section{Contents}

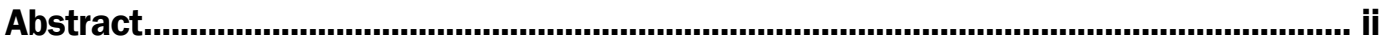

Figures and Tables.............................................................................................................

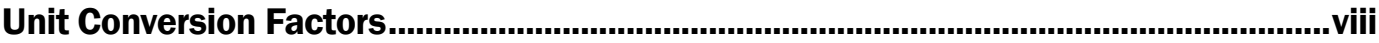

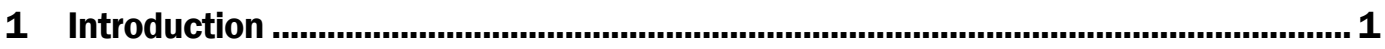

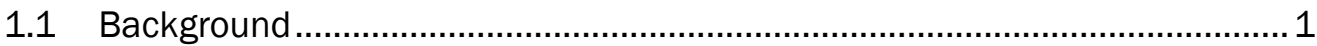

1.2 Objectives...................................................................................... 4

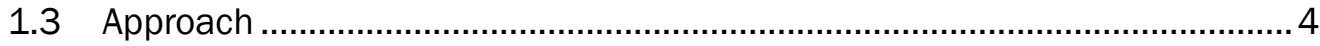

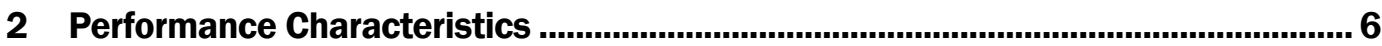

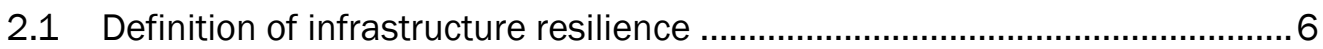

2.2 Performance characteristics and measurements ...................................... 9

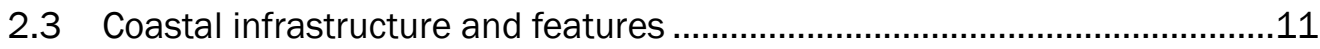

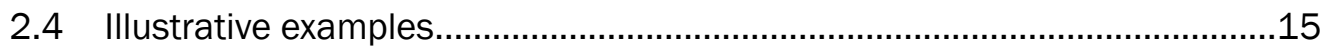

2.4.1 Beaches after Hurricane Sandy with selected case studies ................................. 16

2.4.2 Levees and floodwalls of New Orleans ............................................................ 19

2.4.3 Surge barrier at Lake Borgne ............................................................................. 20

2.4.4 Drainage and pumping of floodwater for New Orleans ...................................... 21

3 Measurement of Resilience..................................................................................23

3.1 Available resilience metrics and their characteristics.............................. 23

3.2 Practical resilience metrics...................................................................... 30

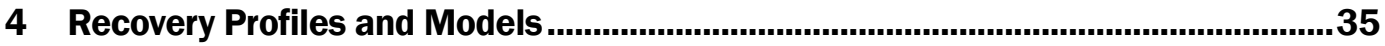

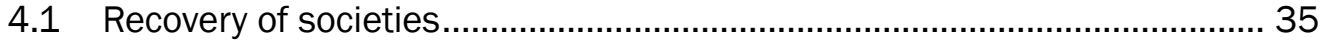

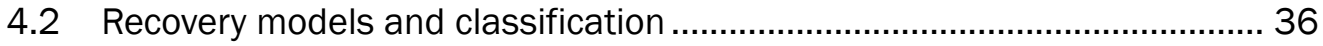

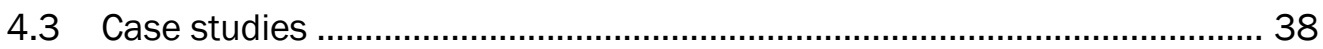

4.3.1 Case Study I: Hurricane Katrina and New Orleans (2005)................................... 38

4.3.2 Case Study II: Highway I-35W Mississippi River Bridge collapse (2007)............... 39

4.3.3 Case Study III: The World Trade Center collapse (2001) ....................................... 39

5 Decision Analysis for Enhancing Resilience ..............................................................40

6 Summary and Future Work ................................................................................... 41

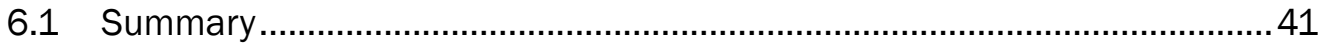

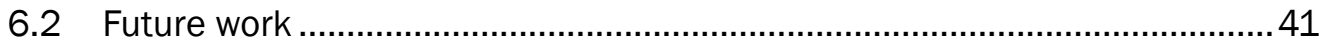

6.2.1 Coastal features: Multiple events, erosion, nourishment, and failure................... 41

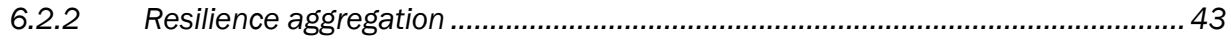

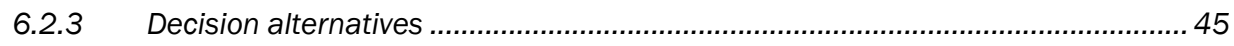

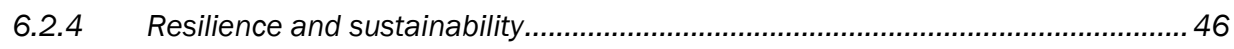

6.2.5 Resilience, sustainability, and asset management ........................................... 48 


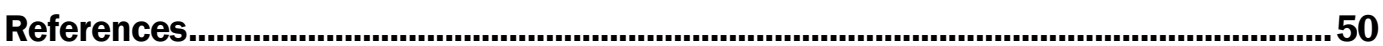

Report Documentation Page 


\section{Figures and Tables}

\section{Figures}

Figure 1. Perceived risk landscape in 2011 (World Economic Forum 2011)....................... 3

Figure 2. Sea Bright to Manasquan Beach, New Jersey (USACE 2013a).......................... 17

Figure 3. Locations (in red) of severe damage to hurricane protection

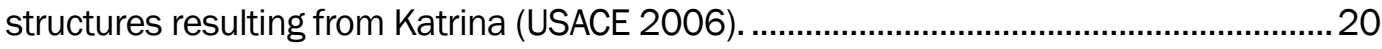

Figure 4. Failure modes and associated performance measurements for

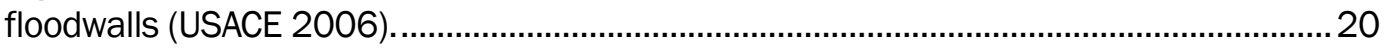

Figure 5. The HSDRRS for southeast Louisiana (Huntsman 2011).................................. 21

Figure 6. Comparison of flooding from Katrina (left) to a hypothetical condition of no breaching and full pumping capacity (right) for Orleans East Bank (USACE

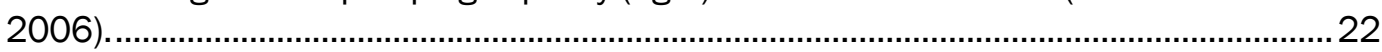

Figure 7. The resilience properties and triangle............................................................ 24

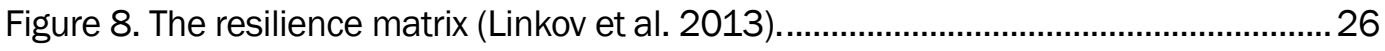

Figure 9. Proposed definitions of resilience metrics (adapted from Ayyub 2014a)........... 27

Figure 10. Fundamental resilience Case I of linear recovery.............................................. 31

Figure 11. A Poisson process of a stressor with varied intensity......................................... 31

Figure 12. Fundamental resilience Case II of one-step (a) and two-step (b)

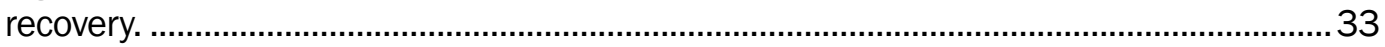

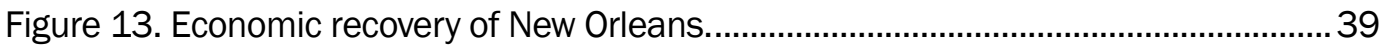

Figure 14. Erosion and accretion processes of built shorelines during storms

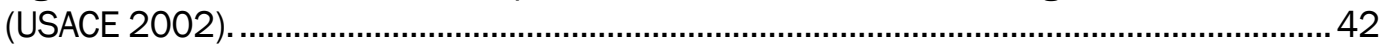

Figure 15. Performance under multiple events.............................................................. 43

Figure 16. System resilience aggregate based on two identical resilience components in series, where $n=$ number of components in series (Ayyub

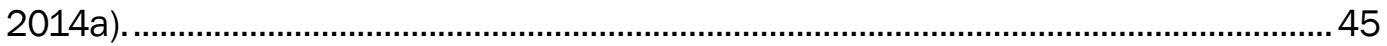

Figure 17. Case 6 where R and S are perfectly dependent with S nested in R................. 48

\section{Tables}

Table 1. Estimated value of insured coastal properties vulnerable to hurricanes

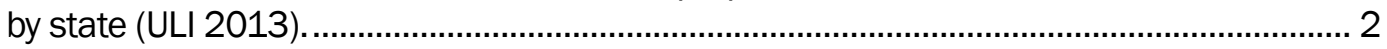

Table 2. A comparison of Hurricanes Katrina and Sandy.................................................. 3

Table 3. Systems and performance measurements (Ayyub 2014a)................................... 10

Table 4. Examples of natural and nature-based features relevant to coastal

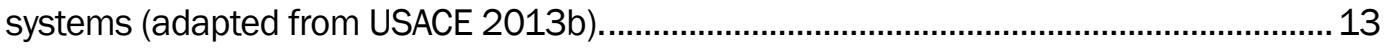

Table 5. Examples of structural features relevant to coastal systems (adapted from USACE 2013b).

Table 6. Examples of non-structural features relevant to coastal systems (adapted from USACE 2013b)........................................................................................ 15

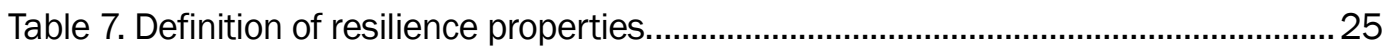


Table 8. Selected sustainability definitions (adapted after Webb and Ayyub

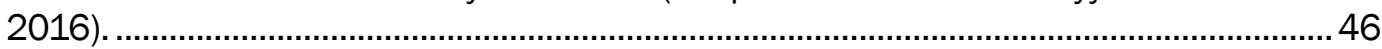




\section{Preface}

This study was funded by the U.S. Army Corps of Engineers, Headquarters (HQUSACE), Project 454623, Navigation Systems (NavSys) Research Program, work unit “Tools and Metrics for Coastal Resilience.” NavSys is administered at the U.S. Army Engineer Research and Development Center (ERDC), Coastal and Hydraulics Laboratory (CHL), under the USACE Navigation Research and Development Program. At the time this study was conducted, Mr. Jeff E. McKee was HQUSACE Navigation Business Line Manager overseeing NavSys; Mr. W. Jeff Lillycrop (ERDCCHL) was the Technical Director for Navigation, and Research, Development, and Technology Transfer portfolio; and Mr. Eddie Wiggins (ERDC-CHL) was the NavSys Program Manager. The Principal Investigator for this study was Dr. Julie D. Rosati (ERDC-CHL).

The work was performed by BMA Engineering, Inc., Potomac, MD, for the Coastal Processes Branch of the Flood and Storm Protection Division, ERDC-CHL. At the time of publication of this report, Ms. Ashley Frey was Chief of the Coastal Processes Branch, and Dr. Cary Talbot was Chief of the Flood and Storm Protection Division, ERDC-CHL. The Deputy Director of ERDC-CHL was Mr. Jeffrey R. Eckstein, and the Director of ERDC-CHL was Dr. Ty V. Wamsley.

COL Ivan P. Beckman was the Commander of ERDC, and Dr. David W. Pittman was the Director of ERDC. 


\section{Unit Conversion Factors}

\begin{tabular}{|l|l|l|}
\hline Multiply & By & To Obtain \\
\hline feet & 0.3048 & meters \\
\hline
\end{tabular}




\section{Introduction}

\subsection{Background}

According to the United Nations Office for Disaster Risk Reduction (UNISDR 2012), half of the world's inhabitants and the vast majority of property and wealth are concentrated in urban centers situated in locations already prone to major disasters, such as earthquakes and severe droughts, and along flood-prone coastlines. It also reported that the 2011 natural disasters resulted in $\$ 366$ billion in direct damages and 29,782 fatalities worldwide. During that year, storms and floods accounted for up to $70 \%$ of the 302 natural disasters. It is anticipated that such disasters would occur with increasing trends of both storm rates and intensity and increasing potential impacts due to a combined effect of climate change and increased coastal inventory of assets (Ayyub et al. 2012). The Urban Land Institute provided exposure estimates based on data as provided in Table 1 with the numeric figures that include residential and commercial properties (ULI 2013). The total exposures in Table 1 are estimates as the actual total value of all property in the state that is insured or can be insured, including the full replacement value of structures and their contents, additional living expenses, and the time value of business interruption coverage. The value of insurable properties along the U.S. Gulf and East coasts was estimated to be more than $\$ 10$ trillion in 2012, an increase of almost $15 \%$ from 2007.

Risk perceptions of the risk landscape as assessed at the 2011 World Economic Forum place storms and climate change at high levels as summarized in Figure 1. These perceptions are not without warrant. The impacts of super storms, such as the 2005 Hurricane Katrina and the 2012 Hurricane Sandy, were unforeseen. These two hurricanes are comparatively summarized in Table 2 according to selected attributes. These levels have attracted the attention of policymakers and have spurred the reexamination of engineering, planning, and mitigation practices.

Enhancing system resilience at varied levels could lead to massive savings through risk reduction and expeditious recovery. The rational management of such reduction and recovery is facilitated by an appropriate definition of resilience and associated metrics. It is essential to develop metrics using effective and rational definitions. The metrics 
should also meet a set of requirements necessary to link them to other metrics and enable aggregation at a system level (Ayyub 2014a, 2015).

Table 1. Estimated value of insured coastal properties vulnerable to hurricanes by state (ULI 2013).

\begin{tabular}{|l|l|l|l|}
\hline Coastal States & $\begin{array}{l}\text { Coastal Exposure } \\
\mathbf{2} 2012 \text { U.S. Billions) }\end{array}$ & $\begin{array}{l}\text { Total Exposure } \\
(\mathbf{2 0 1 2} \text { U.S. Billions) }\end{array}$ & $\begin{array}{l}\text { Coastal as a } \\
\text { Percentage of Total }\end{array}$ \\
\hline Florida & $\$ 2,800.8$ & $\$ 3,562.7$ & $79 \%$ \\
\hline New York & $2,679.5$ & $4,385.7$ & 61 \\
\hline Texas & $1,143.5$ & $4,406.7$ & 26 \\
\hline Massachusetts & 807.2 & $1,505.1$ & 54 \\
\hline New Jersey & 706.5 & $2,081.2$ & 34 \\
\hline Connecticut & 542.5 & 843.8 & 64 \\
\hline Louisiana & 275.1 & 790.4 & 35 \\
\hline South Carolina & 229.6 & 814.7 & 28 \\
\hline Virginia & 176.7 & $1,685.9$ & 10 \\
\hline North Carolina & 159.6 & $1,756.2$ & 9 \\
\hline Maine & 157.7 & 273.6 & 58 \\
\hline Alabama & 118.7 & 903.9 & 13 \\
\hline Georgia & 101.8 & $1,861.7$ & 5 \\
\hline Delaware & 76.9 & 200.5 & 38 \\
\hline New Hampshire & 61.0 & 259.9 & 23 \\
\hline Mississippi & 59.0 & 464.5 & 13 \\
\hline Rhode Island & 55.6 & 199.5 & 28 \\
\hline Maryland & 17.1 & $1,262.2$ & 1 \\
\hline Total, coastal states & $\$ 10,168.8$ & $\$ 27,258.3$ & $37 \%$ \\
\hline U.S. total & $\$ 10,168.8$ & $\$ 62,091.1$ & $16 \%$ \\
\hline
\end{tabular}


Figure 1. Perceived risk landscape in 2011 (World Economic Forum 2011).

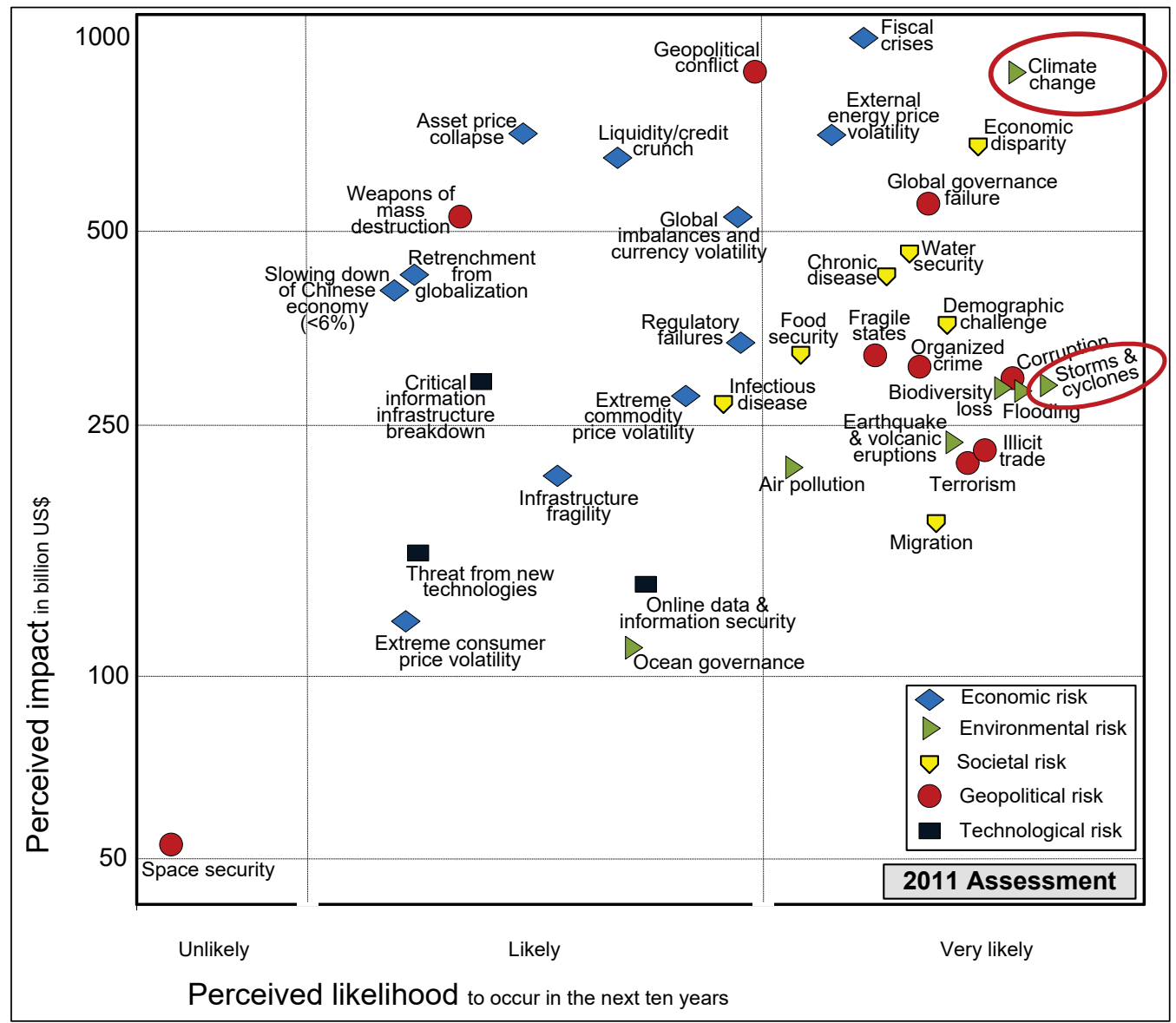

Table 2. A comparison of Hurricanes Katrina and Sandy.

\begin{tabular}{|l|l|l|}
\hline Attribute & Hurricane Katrina & Hurricane Sandy \\
\hline Date & $2005-08-23$ & $2012-10-25$ \\
\hline $\begin{array}{l}\text { The Storm } \\
\text { (Wikipedia) }\end{array}$ & & \\
& & \\
\hline Fatalities & 1,833 & 121 \\
\hline Property damage & $\$ 99.5 \mathrm{~b}(2016$ USD) & $\$ 88.4 \mathrm{~b}$ NY \& NJ (2016 USD) \\
\hline Homes destroyed & 214,700 in LA & 305,000 in NY \\
\hline Power outages & 800,000 homes or & 2.2 million homes or businesses \\
\hline Businesses impacted & 18,700 & 265,300 \\
\hline
\end{tabular}




\subsection{Objectives}

Enhancing system resilience through a combination of infrastructure, flood and storm mitigation, community, and environmental measures has the potential to reduce risk of hazards and increase the speed of recovery for coastal and inland watersheds. To best understand existing resilience capacities for these complex systems, resilience metrics are needed to quantify the capacity to withstand damages, rapidly recover, and adapt to future change. Existing metrics do not always lend themselves easily and intuitively to practical applications in effective and efficient manners. The U.S. Army Corps of Engineers (USACE) requires consistent, transparent, unbiased, quantitative metrics with which to understand the resiliency of complex systems relating coastal infrastructure for coastal and storm damage reduction, navigation, and environmental missions. This study is part of the USACE Coastal Systems Resilience Initiative.

The technical objectives of this research are to develop practical resilience metrics for coastal infrastructure by adopting a resilience definition and setting requirements and axiomatic principles, illustrating resilience metrics from selected infrastructure types, identifying research gaps, and providing recommendations on future research. Outcomes from this effort have high potential technical merits in advancing the USACE capabilities in defining, quantifying, and assessing coastal and watershed system resilience.

Coastal infrastructure includes natural, nature-based, structural, and nonstructural features. These features are identified and categorized based on providing services primarily to humans with other ecosystem considerations. The interactions among the features, users, and services pose challenges in creating hierarchies and aggregation from features to systems to system of systems. Ultimately these features and systems support community resilience including its welfare.

\subsection{Approach}

This report examines and provides appropriate performance metrics for coastal infrastructure with illustrative examples and develops and provides practical resilience metrics. Chapter 2 reviews many existing definitions of resilience to propose a definition applicable to infrastructure resilience that is used herein. It also discusses available performance characteristics of infrastructure features and illustrates the selection of these methods 
through four examples: (1) beaches after hurricane Sandy, (2) the levees and floodwalls of New Orleans, (3) the surge barrier at Lake Borgne, and (4) the drainage and pumping of floodwater for New Orleans. Chapters 3 and 4 focus on measurement science related to resilience and recovery profiles and models, respectively. Chapter 3 identifies available methodologies for quantifying resilience and recommends a set of practical resilience metrics for infrastructure. Chapter 4 is primarily concerned with the concept of recovery - a critical aspect of understanding system performance in response to disturbance-and includes three case studies to illustrate recovery measures. Chapter 5 brings these concepts to help inform decisions for enhancing resilience and is followed by Chapter 6 that provides a summary and suggestions for future work. 


\section{Performance Characteristics}

\subsection{Definition of infrastructure resilience}

An appropriate definition of resilience is essential for developing practical resilience metrics. Such metrics are provided in Chapter 3. Resilience definitions refer to system functions performances. As a result, system performance receives special attention in this chapter.

The concept of resilience appears in different domains ranging from ecology to psychology and psychiatry to infrastructure systems. It was formally introduced in ecology, defined as the persistence of relationships within a system (Holling 1973), and measured by the system's ability to absorb change-state variables, driving variables and parameters and still persist. Several reputable entities defined resilience in their high-impact documents, most notably the following (Ayyub 2014a):

- In the Presidential Policy Directive (PPD-21, 2013) on Critical Infrastructure Security and Resilience, the "term resilience means the ability to prepare for and adapt to changing conditions and withstand and recover rapidly from disruptions. Resilience includes the ability to withstand and recover from deliberate attacks, accidents, or naturally occurring threats or incidents."

- The USACE defines resilience as the ability to anticipate, prepare for, and adapt to changing conditions and withstand, respond to, and recover rapidly from disruptions. This definition was adopted from the 2013 White House's Executive Order 13653, "Preparing the U.S. for Climate Change" (White House, Office of the Press Secretary 2013).

- The National Research Council (2012) defined resilience as the ability to prepare and plan for, absorb, recover from or more successfully adapt to actual or potential adverse events as a consistent definition with U. S. governmental agency definitions (SDR 2005; DHS 2008; PPD-8 2011) and NRC (2011, 2012).

- The American Society of Civil Engineers (ASCE) Committee on Critical Infrastructure (ASCE Policy Statement 518) (ASCE 2013) states that resilience refers to the capability to mitigate against significant allhazard risks and incidents and to expeditiously recover and reconstitute critical services with minimum damage to public safety and health, the economy, and national security. 
- The National Infrastructure Advisory Council (2009) defines infrastructure resilience as the ability to reduce the magnitude and/or duration of disruptive events. The effectiveness of a resilient system depends upon its ability to anticipate, absorb, adapt to, and/or rapidly recover from a potentially disruptive event.

- The Multidisciplinary Center for Earthquake Engineering Research (MCEER) of the State University of New York at Buffalo lists characteristics of resilience to include robustness, redundancy, resourcefulness, and rapidity (Renschler et al. 2010).

- The United Nations Office for Disaster Risk Reduction (UNISDR, 2005) characterized a resilient city by its capacity to withstand or absorb the impact of a hazard through resistance or adaptation, which enable it to maintain certain basic functions and structures during a crisis and bounce back or recover from an event.

- The Civil Contingencies Secretariat of the Cabinet Office, London, UK (2003), defined resilience as the ability of a system or organization to withstand and recover from adversity.

Additional resilience definitions are available in the literature (see Cimellaro et al. 2016). Ayyub (2014a) suggested a resilience definition that builds on the PPD-21 (2013). The suggested definition lends itself to quantification and measurement as follows:

Resilience notionally means the ability to prepare for and adapt to changing conditions and withstand and recover rapidly from disruptions. Resilience includes the ability to withstand and recover from disturbances of the deliberate attack types, accidents, or naturally occurring threats or incidents.

Ayyub (2015) examined the suitability of definitions by starting with classifying interpretive definitions from the lowest to highest level of precision degeneracy (i.e., increased ambiguity) as follows:

1. An intension definition specifies the necessary and sufficient conditions for a thing to belong to a particular set. Example intension definitions are "Earth is a planet" and "Asia is a continent of Earth." The definition in this case provides a one-to-one conceptual mapping.

2. An extension definition specifies a list naming every object that is a member of a specific set. An example extension definition is "The continents of Earth are Asia, Africa, North America, South America, 
Antarctica, Europe, and Australia." The definition in this case provides a one-to-many mapping.

3. An inclusion definition specifies the members of a class by meeting particular conditions or requirements. For example, "Living things are systems that reproduce for sustainment and survival."

4. An exclusion definition specifies the members of a class by pointing out things that do belong to the class by not meeting particular conditions or requirements. For example, "Living things are not rocks, water, oil, air, or fire."

5. Combinations. Combinations of the five classes lead to other definition types as long as the combined types have internal consistency. Generally a definition from a higher precision level can be combined with others of lower levels, but not vice versa.

The above resilience definition has intension and inclusion class features. A definition that belongs to the intension class (Ayyub 2015) is as follows:

The resilience of a system is the persistence of its functions and performances under uncertainty in the face of disturbances.

This definition is intended to have a broad use ranging from infrastructures to networks to communities. It not only complements the USACE definition but also refines concepts further to enable quantification. It enables the measurement of resilience through metrics by meeting the following requirements as demonstrated by Ayyub (2014a): (1) building on previous notional definitions; (2) considering initial and residual strength (i.e., capacity and robustness); (3) accounting for abilities to prepare and plan for, absorb, recover from, or adapt to adverse events; (4) treating disturbances as events with occurrence rates of stochastic processes; (5) permitting the use of several performance attributes; (6) accounting for changes over time (e.g., aging or improvements); (7) considering full or partial recovery and times to recovery; (8) considering potential enhancements to system performance after recovery; (9) being compatible with other familiar notions such as reliability and risk; and (10) enabling the development of resilience metrics with meaningful units.

The definition by Ayyub (2015) is consistent with the ISO (2009) risk definition of the "effect of uncertainty on objectives." The resilience 
definition includes three key words that offer a basis for quantification. These words are listed in a suggested order for their analysis as follows:

- System's performance defined in terms of requirements or objectives, and examined in the form of output, throughput, structural integrity, lifecycle cost, etc.

- Uncertainty relating to events such as storms, disturbance, conditions, system states, etc.

- Persistence examined in terms of enduring the events, recovery, continuance and/or resumption of performance.

Most resilience definitions do not always lend themselves naturally and intuitively to the development of consistent resilience metrics with clear relationships to the most relevant metrics of the abstract notions of reliability and risk. The use of the operative word of ability, as provided by other definitions, sometimes has resulted in setting the measurement process on tracks that focus on the abilities rather than the outcomes of these abilities. The primary outcome of these abilities is the continuance of the performance of a system, including bouncing-back, a characteristic that could be appropriately termed as performance persistence for a particular function of the system. Performance persistence would naturally set measurement in terms of availability of the performance or continuance of system's states of normalcy through time. Subsequent sections of this paper provide metrics based on the proposed definition that meet logically consistent requirements drawn partly from measure theory as provided by Ayyub (2014a) and provide a sound basis for the development of effective decision-making tools for multi-hazard environments.

\subsection{Performance characteristics and measurements}

Defining the "resilience of a system as the persistence of its functions and performances under uncertainty in the face of disturbances" requires defining and characterizing functions and performances. The function of an infrastructure feature or system is the purpose natural to or intended for the infrastructure feature or system whereas infrastructure performance is the accomplishment of tasks set for the system or its parts by the society that builds, operates, uses, or is neighbor to that infrastructure (NRC 1996).

Infrastructure performances are tied to what a system is expected to provide to fulfill particular needs through its functions. Appropriate performance attributes and measurements can be selected based on their 
appropriateness for quantifying resilience. The primary requirement for performance attributes and measurements is suitability for measuring resilience.

Practical resilience models, as provided in Chapter 3, are applicable to varied coastal infrastructure systems. The primary basis for quantifying resilience is the definition of performance $(Q)$ at the appropriate system level with meaningful and appropriate units, followed by the development of an appropriate breakdown for this performance, using what is termed herein as performance segregation. The performance segregation should be based on some system-level logic that relates the components of the performance breakdown to the overall performance at the system level through systems modeling. System models can be used to aggregate the performance of components to assess system-level performance. Such performance segregation and aggregation analysis is essential for examining the resilience of coastal infrastructure systems. The uncertainties associated with the performance components can be modeled as random variables with any necessary performance-related events to use Boolean algebra and the mathematics of probability to characterize the performance $Q$. The units of performance at the system level vary depending on the system type and the objectives of the analysis. Table 3 lists examples of performance types and units of measurement for selected systems for demonstration purposes (Ayyub 2014a).

Table 3. Systems and performance measurements (Ayyub 2014a).

\begin{tabular}{|l|l|l|}
\hline Systems & Performance & Units \\
\hline Buildings & Space availability & Area per day \\
\hline $\begin{array}{l}\text { Other structures: Highway } \\
\text { bridges }\end{array}$ & Throughput traffic & Count per day \\
\hline $\begin{array}{l}\text { Facilities: Water treatment } \\
\text { plants }\end{array}$ & Water production capacity & Volume per day \\
\hline Infrastructure: Water delivery & Water available for consumption & Volume \\
\hline Dunes and beaches & Protection provided & $\begin{array}{l}\text { Level of protection in } \\
\text { terms of surge/wave } \\
\text { height), width and/or } \\
\text { volume }\end{array}$ \\
\hline $\begin{array}{l}\text { Network: Electric power } \\
\text { distribution }\end{array}$ & Power delivered & Power per day \\
\hline Communities & $\begin{array}{l}\text { Economic output } \\
\text { Quality of life (consumption) }\end{array}$ & $\begin{array}{l}\text { Dollars } \\
\text { Dollars }\end{array}$ \\
\hline
\end{tabular}




\subsection{Coastal infrastructure and features}

According to the 2010 U.S. census Bureau (NOAA 2016), 39\% of the U.S. population is concentrated in counties directly on the shoreline, constituting less than $10 \%$ of the total U.S. land area excluding Alaska. Additionally $52 \%$ of the total population lives in counties that drain to coastal watersheds, constituting less than $20 \%$ of U.S. land area, excluding Alaska (see also Table 1). Current population trends in the United States would result in an estimated population increase for coastal counties from 123 million people to nearly 134 million people by 2020 . This increase surpasses the overall population increase. As a result, exposures in terms of population and property at risk would increase, leading to greater future risks due to hazards such as hurricanes, storms, wave action, and global climate change effects such as sea level rise, extreme precipitation, drought, and salt-water intrusion. Coastal areas are at the interface or transition from land to sea, including wetlands and large inland lakes. Wetlands play a critical role in protecting the shore from flooding in addition to providing important habitats for many plant and animal species (e.g., the Everglades as wetlands in southern Florida is home to diverse ecosystems).

Coastal infrastructure has critical roles in providing life and property security and safety. It can be grouped into four categories of interacting features as follows (Bridges et al. 2015):

\section{Natural Features}

Such features are the product of natural processes that created and have evolved them over time through the actions of physical, biological, geologic, and chemical processes. Examples include reefs (e.g., coral and oyster, barrier islands, dunes, beaches, wetlands, and maritime forests).

2. Nature-Based Features

These engineered and built features have the purpose to mimic the characteristics of natural features to provide specific services such as coastal risk reduction (e.g., dunes and beaches).

\section{Structural Features}

These engineered and built features support a range of objectives, including erosion control and storm risk reduction (e.g., seawalls and levees), as well as infrastructure providing economic and social functions (e.g., navigation channels, ports, harbors, and residential housing). 


\section{Nonstructural Features}

They include policy and management features to support a range of objectives, such as storm risk reduction (e.g., floodplain policy and management, flood-proofing and impact reduction, flood warning and preparedness, and relocation).

The relationships and interactions among these features of coastal systems are important in determining coastal vulnerability, reliability, risk and resilience. Tables 4, 5, and 6 provide examples of natural, nature-based, structural, and non-structural features relevant to coastal infrastructure systems (adapted from USACE 2013b).

The performance of these natural features can be defined and measured like any other coastal infrastructure. Wamsley et al. (2015) provide coastal vulnerability metrics that could be used to identify performance measurements. Cunniff and Schwartz (2015) list performance considerations that are suitable for natural infrastructure and naturebased measures as a basis for identifying coastal risk reduction features. Cutter (2008) provides candidate variables for measuring resilience of natural systems and exposures, such as area of dunes, dune dimensions, erosion rate, etc. 
Table 4. Examples of natural and nature-based features relevant to coastal systems (adapted from USACE 2013b).

\begin{tabular}{|c|c|c|c|c|c|}
\hline Types & $\begin{array}{l}\text { Dunes and } \\
\text { Beaches }\end{array}$ & $\begin{array}{l}\text { Vegetated } \\
\text { Features (e.g., } \\
\text { marshes) }\end{array}$ & $\begin{array}{l}\text { Oyster and } \\
\text { Coral Reefs }\end{array}$ & Barrier Islands & $\begin{array}{l}\text { Maritime } \\
\text { Forests/Shrub } \\
\text { Communities }\end{array}$ \\
\hline Benefits & $\begin{array}{l}\text { Breaking of } \\
\text { offshore waves, } \\
\text { Attenuation of } \\
\text { wave energy, } \\
\text { Reduction or } \\
\text { prevention of } \\
\text { inland water } \\
\text { transfer }\end{array}$ & $\begin{array}{l}\text { Breaking of } \\
\text { offshore waves, } \\
\text { Attenuation of } \\
\text { wave energy, } \\
\text { Reduction or } \\
\text { prevention of } \\
\text { inland water } \\
\text { transfer, } \\
\text { Increased } \\
\text { infiltration }\end{array}$ & $\begin{array}{l}\text { Breaking of } \\
\text { offshore } \\
\text { waves, } \\
\text { Attenuation } \\
\text { of wave } \\
\text { energy, } \\
\text { Slowing of } \\
\text { inland water } \\
\text { transfer }\end{array}$ & $\begin{array}{l}\text { Wave } \\
\text { attenuation } \\
\text { and/or } \\
\text { dissipation, } \\
\text { Sediment } \\
\text { stabilization }\end{array}$ & $\begin{array}{l}\text { Wave } \\
\text { attenuation } \\
\text { and/or } \\
\text { dissipation, } \\
\text { Shoreline } \\
\text { stabilization, } \\
\text { Soil retention }\end{array}$ \\
\hline $\begin{array}{l}\text { Performance } \\
\text { factors }\end{array}$ & $\begin{array}{l}\text { Berm height } \\
\text { and width, } \\
\text { Beach slope, } \\
\text { Sediment grain } \\
\text { size and supply, } \\
\text { Dune height, } \\
\text { crest, and } \\
\text { width, } \\
\text { Presence of } \\
\text { vegetation }\end{array}$ & $\begin{array}{l}\text { Marsh, } \\
\text { wetland, or } \\
\text { submerged } \\
\text { aquatic } \\
\text { vegetation } \\
\text { elevation and } \\
\text { continuity, } \\
\text { Vegetation type } \\
\text { and density, } \\
\text { Spatial extent }\end{array}$ & $\begin{array}{l}\text { Reef width, } \\
\text { elevation, } \\
\text { and } \\
\text { roughness }\end{array}$ & $\begin{array}{l}\text { Island } \\
\text { elevation, } \\
\text { length, and } \\
\text { width, } \\
\text { Land cover, } \\
\text { Breach } \\
\text { susceptibility, } \\
\text { Proximity to } \\
\text { mainland } \\
\text { shore }\end{array}$ & $\begin{array}{l}\text { Vegetation } \\
\text { height and } \\
\text { density, } \\
\text { Forest } \\
\text { dimension, } \\
\text { Sediment } \\
\text { composition, } \\
\text { Platform } \\
\text { elevation }\end{array}$ \\
\hline $\begin{array}{l}\text { Performance } \\
\text { measurements } \\
\text { suitable for } \\
\text { resilience } \\
\text { quantification } \\
\text { (Examples) }\end{array}$ & $\begin{array}{l}\text { Example: See } \\
\text { Section } 2.4 .1 \\
\text { on beaches } \\
\text { after hurricane } \\
\text { Sandy }\end{array}$ & $\begin{array}{l}\text { Example: See } \\
\text { Section } 2.4 .1 \\
\text { on beaches } \\
\text { after hurricane } \\
\text { Sandy }\end{array}$ & & & \\
\hline
\end{tabular}


Table 5. Examples of structural features relevant to coastal systems (adapted from USACE 2013b).

\begin{tabular}{|c|c|c|c|c|c|}
\hline $\begin{array}{l}\text { Structural } \\
\text { Feature Types }\end{array}$ & Levees & $\begin{array}{l}\text { Storm Surge } \\
\text { Barriers }\end{array}$ & $\begin{array}{l}\text { Seawalls and } \\
\text { Revetments }\end{array}$ & Groins & $\begin{array}{l}\text { Detached } \\
\text { Breakwaters }\end{array}$ \\
\hline $\begin{array}{l}\text { Benefits and } \\
\text { processes }\end{array}$ & $\begin{array}{l}\text { Surge and wave } \\
\text { attenuation } \\
\text { and/or } \\
\text { dissipation, } \\
\text { Reduced } \\
\text { flooding, } \\
\text { Reduced risk } \\
\text { for vulnerable } \\
\text { areas }\end{array}$ & $\begin{array}{l}\text { Surge and wave } \\
\text { attenuation, } \\
\text { Reduced } \\
\text { salinity } \\
\text { intrusion }\end{array}$ & $\begin{array}{l}\text { Reduced } \\
\text { flooding, } \\
\text { Reduced wave } \\
\text { overtopping, } \\
\text { Shoreline } \\
\text { stabilization } \\
\text { behind } \\
\text { structure }\end{array}$ & $\begin{array}{l}\text { Shoreline } \\
\text { stabilization }\end{array}$ & $\begin{array}{l}\text { Shoreline } \\
\text { stabilization } \\
\text { behind } \\
\text { structure, } \\
\text { Wave } \\
\text { attenuation }\end{array}$ \\
\hline $\begin{array}{l}\text { Performance } \\
\text { factors }\end{array}$ & $\begin{array}{l}\text { Levee height, } \\
\text { crest width, } \\
\text { and slope, } \\
\text { Wave height } \\
\text { and period, } \\
\text { Water level }\end{array}$ & $\begin{array}{l}\text { Barrier height, } \\
\text { Wave height, } \\
\text { Wave period, } \\
\text { Water level }\end{array}$ & $\begin{array}{l}\text { Wave height, } \\
\text { Wave period, } \\
\text { Water level, } \\
\text { Scour } \\
\text { protection }\end{array}$ & $\begin{array}{l}\text { Groin length, } \\
\text { height, } \\
\text { orientation, } \\
\text { permeability, } \\
\text { and spacing, } \\
\text { Depth at } \\
\text { seaward end, } \\
\text { Wave height, } \\
\text { Water level, } \\
\text { Longshore } \\
\text { transportation } \\
\text { rates and } \\
\text { distribution }\end{array}$ & $\begin{array}{l}\text { Breakwater } \\
\text { height and } \\
\text { width, } \\
\text { Breakwater } \\
\text { permeability, } \\
\text { proximity to } \\
\text { shoreline, } \\
\text { orientation, } \\
\text { and spacing, } \\
\text { Quantity of } \\
\text { beach fill } \\
\text { placed to lee } \\
\text { of } \\
\text { breakwaters }\end{array}$ \\
\hline $\begin{array}{l}\text { Performance } \\
\text { measurements } \\
\text { suitable for } \\
\text { resilience } \\
\text { quantification } \\
\text { (Examples) }\end{array}$ & $\begin{array}{l}\text { Example: See } \\
\text { Section } 2.4 .2 \\
\text { on New Orleans } \\
\text { Levees }\end{array}$ & $\begin{array}{l}\text { Example: See } \\
\text { Section } 2.4 .3 \\
\text { on Lake Borgne } \\
\text { surge barrier }\end{array}$ & & & \\
\hline
\end{tabular}


Table 6. Examples of non-structural features relevant to coastal systems (adapted from USACE 2013b).

\begin{tabular}{|c|c|c|c|c|}
\hline $\begin{array}{l}\text { Non-structural } \\
\text { Feature Types }\end{array}$ & $\begin{array}{l}\text { Floodplain Policy } \\
\text { and Management }\end{array}$ & $\begin{array}{l}\text { Flood-proofing and } \\
\text { Impact Reduction }\end{array}$ & $\begin{array}{l}\text { Flood Warning and } \\
\text { Preparedness }\end{array}$ & Relocation \\
\hline $\begin{array}{l}\text { Benefits and } \\
\text { processes }\end{array}$ & $\begin{array}{l}\text { Improved and } \\
\text { controlled } \\
\text { floodplain } \\
\text { development, } \\
\text { Reduced } \\
\text { opportunity for } \\
\text { damages, } \\
\text { Improved natural } \\
\text { coast environment }\end{array}$ & $\begin{array}{l}\text { Reduced } \\
\text { opportunity for } \\
\text { damages, } \\
\text { Increased } \\
\text { community } \\
\text { resiliency, } \\
\text { No increase in } \\
\text { flood potential } \\
\text { elsewhere }\end{array}$ & $\begin{array}{l}\text { Reduced } \\
\text { opportunity for } \\
\text { damages, } \\
\text { Increased } \\
\text { community } \\
\text { resiliency, } \\
\text { Improved public } \\
\text { awareness and } \\
\text { responsibility }\end{array}$ & $\begin{array}{l}\text { Reduced } \\
\text { opportunity for } \\
\text { damages, } \\
\text { No increase in } \\
\text { flood potential } \\
\text { elsewhere, } \\
\text { Improved natural } \\
\text { coast environment }\end{array}$ \\
\hline $\begin{array}{l}\text { Performance } \\
\text { factors }\end{array}$ & $\begin{array}{l}\text { Wave height, } \\
\text { Water level, } \\
\text { Storm duration, } \\
\text { Agency } \\
\text { collaboration }\end{array}$ & $\begin{array}{l}\text { Wave height, } \\
\text { Water level, } \\
\text { Storm duration }\end{array}$ & $\begin{array}{l}\text { Wave height, } \\
\text { Water level, } \\
\text { Storm duration }\end{array}$ & $\begin{array}{l}\text { Wave height, } \\
\text { Water level, } \\
\text { Storm duration }\end{array}$ \\
\hline $\begin{array}{l}\text { Performance } \\
\text { measurements } \\
\text { suitable for } \\
\text { resilience } \\
\text { quantification } \\
\text { (Examples) }\end{array}$ & & $\begin{array}{l}\text { Example: See } \\
\text { Section } 2.4 .4 \text { on } \\
\text { drainage and } \\
\text { pumping of } \\
\text { floodwater for New } \\
\text { Orleans }\end{array}$ & & \\
\hline
\end{tabular}

\subsection{Illustrative examples}

This section provides several examples on how to select appropriate measurements and metrics of performance that are suitable for quantifying resilience. The quantification of resilience is covered in Chapter 3 . The examples correspond to several cases provided in Tables 4 through 6 and are as follows:

- beach and berms after Hurricane Sandy, with Manasquan, NJ, as a case study

- levees of New Orleans

- surge barrier at Lake Borgne

- drainage and pumping of floodwater for New Orleans.

These examples are discussed further in subsequent subsections with corresponding measurements of performance. 


\subsubsection{Beaches after Hurricane Sandy with selected case studies}

Hurricane Sandy produced peak water levels that correspond to levels greater than a 200-year event ( 1 in 200 annual exceedance probability) and greatly exceeded project design levels in many areas (USACE 2013a). Damages resulted throughout the New York City metropolitan area; the New York Bight including New Jersey, along the north shore of Long Island, NY; Connecticut; Rhode Island; southern Massachusetts; and the Atlantic coasts of Delaware, Maryland, and Virginia. Six storm-protection projects consisting of Sea Bright to Manasquan, NJ and NY; Keansburg, East Keansburg, and Laurence Harbor, NJ; Oakwood Beach, NY; Coney Island, NY; Plumb Beach, NY; and Rockaway, NY, were subjected to extreme storm tides and waves (USACE 2013a). These projects reduced storm damage despite the fact that storm tides and waves exceeded design storm levels (USACE 2013a). The beaches served an intended objective of limiting wave-induced structural damages for most of the area.

As an example, the Manasquan Beach, New Jersey, (Figure 2) has the following design characteristics (USACE 2013a):

- Berm elevation North American Vertical Datum 1988 (NAVD88): $7 \cdot 3$ feet ( $\mathrm{ft}$ )

- Berm width: $100 \mathrm{ft}$

- Dune elevation* (NAVD88): $9.3 \mathrm{ft}$

- Dune width: $80 \mathrm{ft}$

- Structure elevation (NAVD88): 15.0 to $20.0 \mathrm{ft}$

- Design event: 35 to 40 years

- Nourishment cycle: 6 years.

*Note: At Sea Bright to Manasquan, there is no dune feature, but there is a $2 \mathrm{ft}$ berm cap and a relatively high seawall along a significant portion of the project. 
Figure 2. Sea Bright to Manasquan Beach, New Jersey (USACE 2013a).

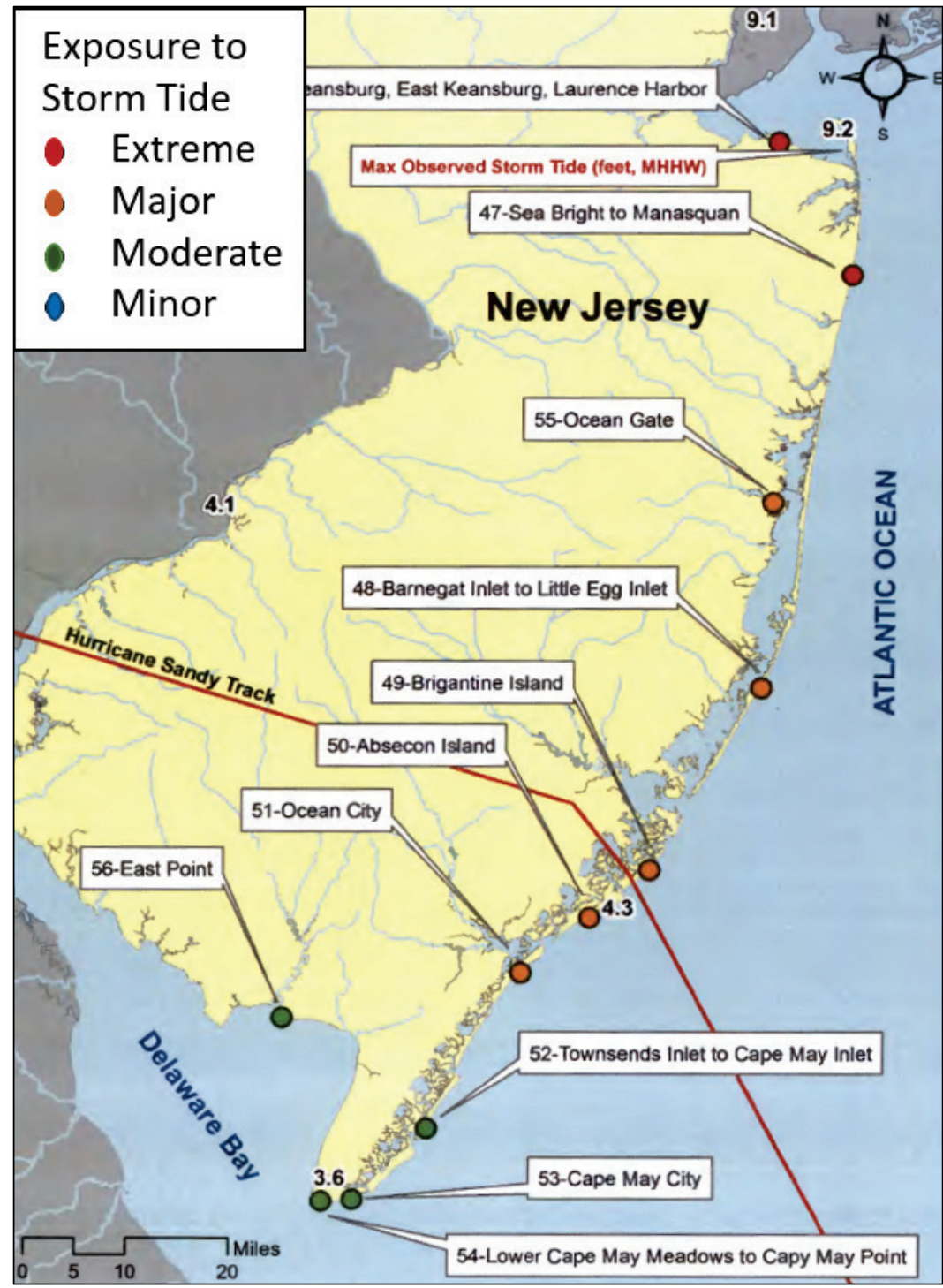

The first renourishment of the Manasquan Beach, New Jersey, Beach occurred in 2002, and no additional renourishment had taken place at the time Hurricane Sandy made landfall in October 2012. Therefore, the prestorm condition of the project stretching from Sea Bright to Manasquan was mostly below design level in elevation. These declines or deficiencies should be accounted for when assessing the resilience of a system back to adequate performance.

The storm tide at the Sea Bright was at an elevation of $16.5 \mathrm{ft}$ (NAVD88), corresponding to greater than a 500-year event. This storm surge resulted in a depth above berm of $9.2 \mathrm{ft}$ and resulted in project overtopping with beach erosion of 4.5 million cubic yards. This overtopping event corresponds to an average drop in beach elevation of 5 to $10 \mathrm{ft}$ with 
variability in berm widths. Sea Bright to Manasquan Inlet were subject to back-bay/peninsula flooding. Many areas also suffered devastating flooding with recorded stages in the tidal rivers as high as $+13 \mathrm{ft}$ (NAVD88). Low-lying areas along the Shark River and Manasquan River were also subject to extensive flooding through the inlets. In Manasquan, 896 buildings were impacted as follows: 2 destroyed, 265 with major damage, 371 with minor damage, and 258 affected.

Based on the USACE (2013a) report, appropriate performance measures for beaches can be identified as follows: (1) beach erosion in million cubic yards, (2) affected buildings in count and square footage to serve any particular reasons such as economic valuation, and (3) storm tide depth above berm in feet. These performances could have varied scales and units of measurement where in some cases a greater number indicates greater performance and in other cases it is the other way around. Such a variation can be easily addressed by defining a complementary performance values in some cases to create consistency where a larger number always means larger performance.

From ecological perspectives, dunes and berms serve other critical functions as integral components of ecosystems. The Department of the Interior (DOI 2015) convened a group of experts and suggested core ecological performance metrics for specific coastal features and projects. Some of these metrics are suitable for measuring performance and could offer a basis for quantifying resilience. Example ecological performance metrics for beaches and dunes are classified into three categories (DOI 2015):

- Biotic

- Vegetation cover of dunes pre- and post-event in square miles

- Fish and wildlife population counts, recruitment, overwintering, stopover, weight, health, etc., relative to other mitigating factors and threats throughout ranges covering sites and species

- Abiotic

- Post-storm volume of sand in the active shoreface in million cubic yards

- Recovery rates of beach and dunes

- Structural

- Beach width, elevation, volume, shoreline position after an event

- Dune characterization, such as height, width, length, texture, substrate, etc. 
Methods based on aerial mapping using lidar for quantifying geomorphic changes are available as provided by Dunkin (2016) and Hapke et al. (2016). These methods could provide the necessary data for measuring and tracking performance of beaches and dunes.

\subsubsection{Levees and floodwalls of New Orleans}

The 2005 Hurricane Katrina resulted in 50 major breaches of the hurricane protection system of New Orleans. Forty-six of the major breaches were due to overtopping that caused erosion behind the walls, eventually causing instability and wall failure. These 46 correspond to $92 \%$ of all the breaches. Other failures were caused by foundation failures induced by the formation of a gap along the canal side of the floodwall according to Figures 3 and 4 (USACE 2006). Figure 4 shows failure modes and confirmation results for the purpose of validation. It is noted herein that risk models are available for hurricane protection systems (e.g., Ayyub et al. 2009a, b).

A primary performance measure for levees is the difference between the high-water mark and the height of the levee. Overtopping can be defined as a failure in performance that might correspond to structural failure. As for the foundation failures, an appropriate performance measure is the tilt angle of the wall due to surge and waves. Other measures (e.g., for subsidence) may include the elevation of the levee that would affect the available height for protection. 
Figure 3. Locations (in red) of severe damage to hurricane protection structures resulting from Katrina (USACE 2006).

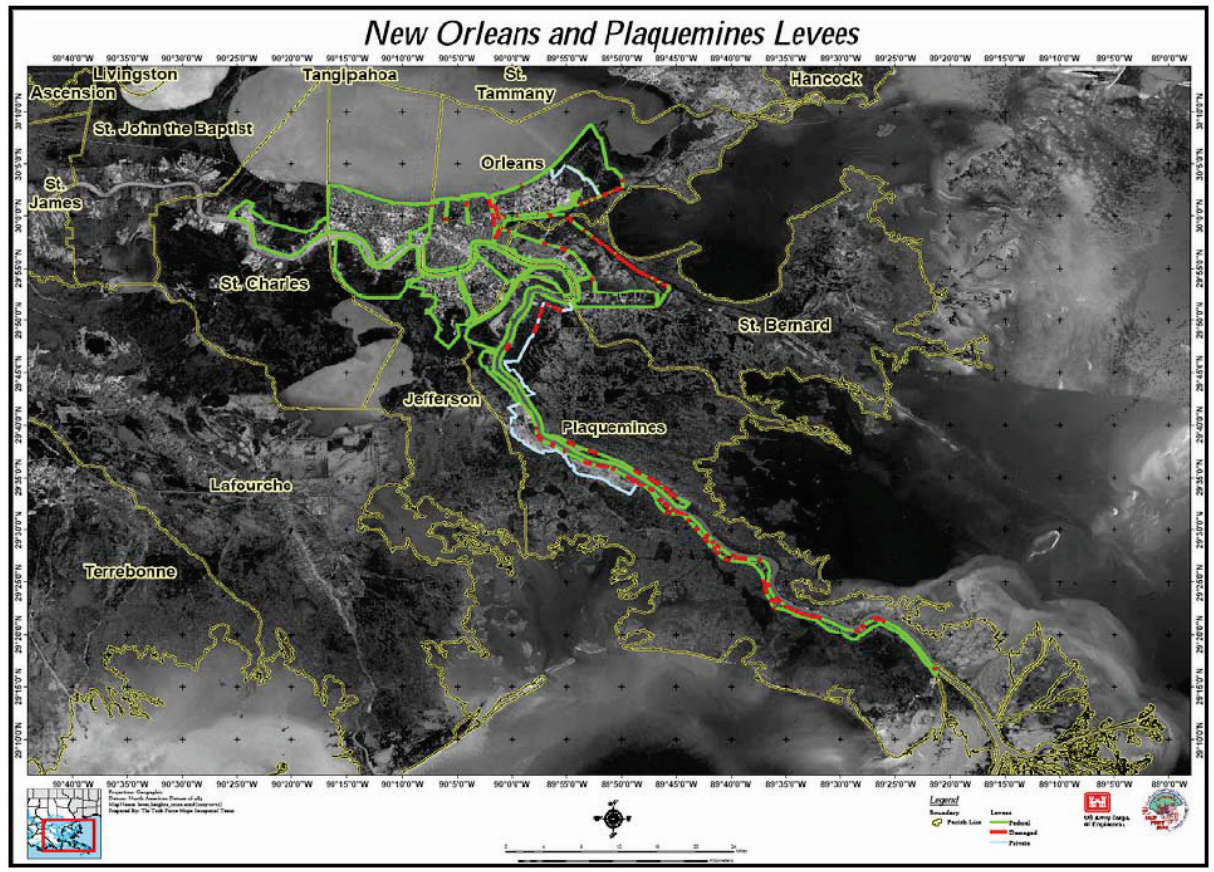

Figure 4. Failure modes and associated performance measurements for floodwalls (USACE 2006).

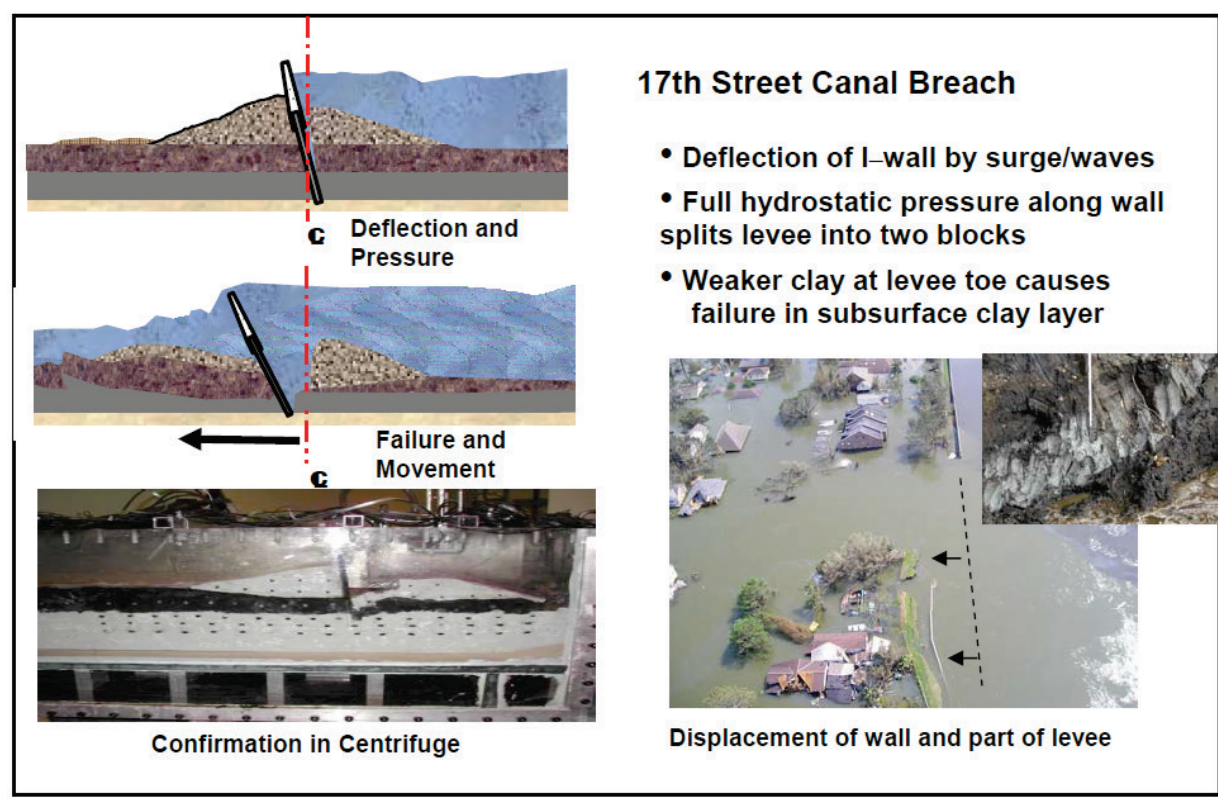

\subsubsection{Surge barrier at Lake Borgne}

The 2005 Hurricanes Katrina and Rita devastated the City of New Orleans and surrounding areas and compelled the USACE to design and construct the Hurricane and Storm Damage Risk Reduction System (HSDRRS) for 
Southeast Louisiana. A key feature of the HSDRRS is the Inner Harbor Navigation Canal and Lake Borgne Surge Barrier. This 10,000 ft long, $26 \mathrm{ft}$ high surge barrier includes three gate structures and a barrier wall that became functional in 2011 (Huntsman 2011). The barrier is near the confluence of the Gulf Intracoastal Waterway and the Mississippi River Gulf Outlet as shown in Figure 5.

A primary performance measure, in this case, is the difference between the high-water mark and the height of the barrier that stands at $26 \mathrm{ft}$. Overtopping can be defined as a failure in performance that might correspond to structural failure. Additional performance measures (e.g., for subsidence) may include the tilt angle of the wall and the elevation of the wall that would affect the available height of the barrier.

Figure 5. The HSDRRS for southeast Louisiana (Huntsman 2011).

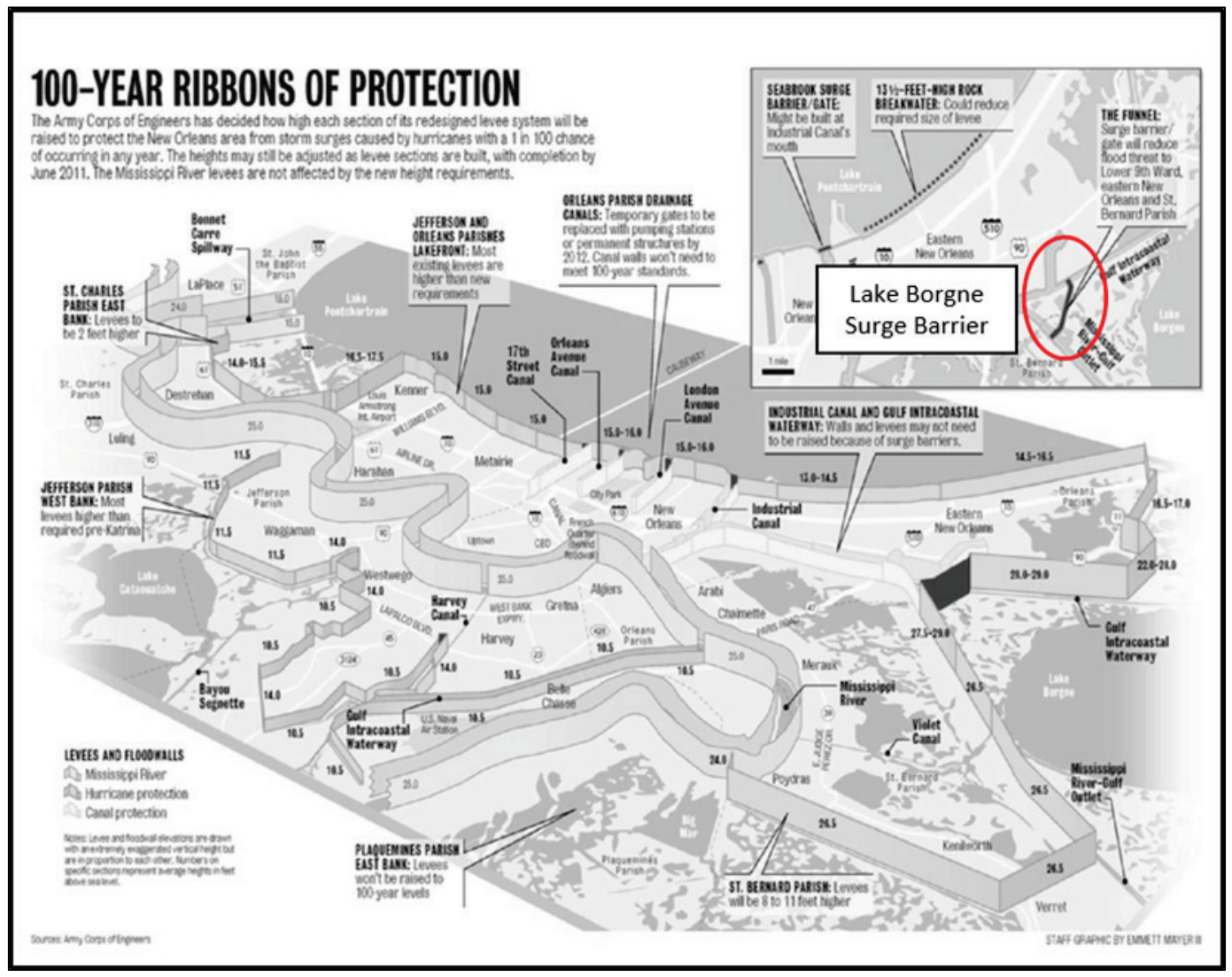

\subsubsection{Drainage and pumping of floodwater for New Orleans}

During the 2005 Hurricane Katrina, the drainage and pumping systems of New Orleans could not carry out their functions nor did they have the capacities and appropriate integration to handle the resulting flooding. 
USACE (2006) simulated the effects if there had been operational capacity, as provided in Figure 6. The figure shows two cases for comparing flooding from Katrina (on the left) to a hypothetical condition of no breaches and full pumping capacity (on the right) for Orleans East Bank. Appropriate performance measures for drainage and pumping are the difference between the demand from an event and the available capacities.

Figure 6. Comparison of flooding from Katrina (left) to a hypothetical condition of no breaching and full pumping capacity (right) for Orleans East Bank (USACE 2006).

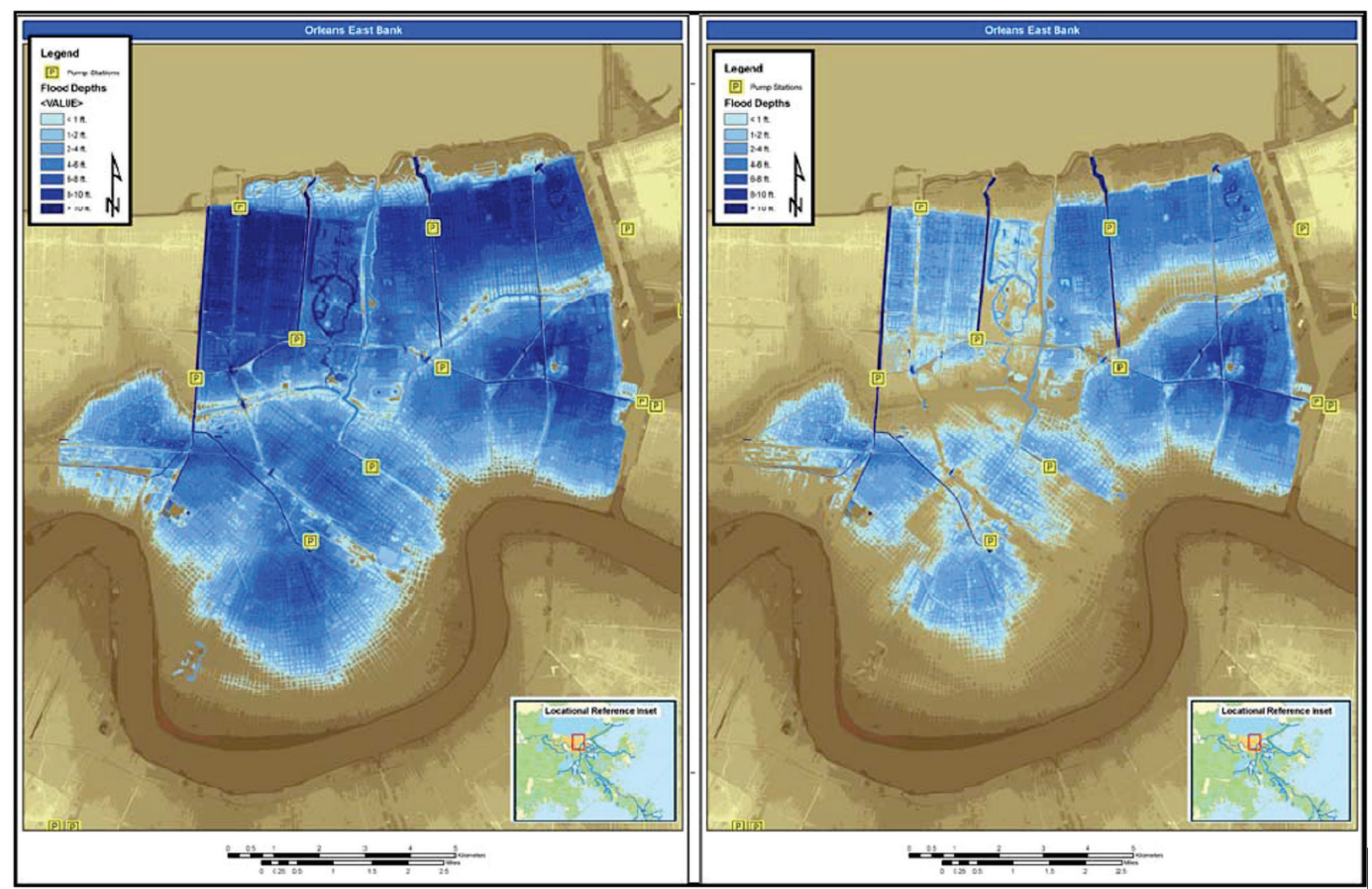




\section{Measurement of Resilience}

Chapter 2 provides resilience definitions that meet a set of necessary requirements followed by performance definitions of coastal infrastructure features to meet their necessary requirements. Keeney and Gregory (2005) set general criterion for metrics by being relevant, unambiguous, direct, operational, understandable, and comprehensive. McKay et al. (2012) examined criteria for ecosystem restoration objectives and metrics. These studies and others inform the primary requirements for the measurement of resilience, which are to (1) meet rules and practices set by measurement theory, (2) offer meaningful units or interpretable values across infrastructure features, (3) be appropriate for aggregation at the system and system of systems levels, (4) offer bases for total economic valuation, and (5) be suitable for tradeoff and benefitcost analyses. Different performances could have varied scales and units of measurement where in some cases a greater number indicates greater performance and in other cases it is the other way around. Such a variation can be easily addressed by defining complementary performance values in some cases to create consistency where a larger number always means larger performance.

\subsection{Available resilience metrics and their characteristics}

Bruneau and Reinhorn (2007) suggested metrics for measuring resiliency based on the size of expected degradation in the quality of an infrastructure by quantifying robustness, redundancy, resourcefulness, and rapidity to recovery. Garbin and Shortle (2007) outlined an approach to quantitatively measure the resilience of a network as the percentage of links damaged versus the network performance and the percentage of nodes damaged versus the network performance. Schultz et al. (2012) discuss the quantification and resilience of integrated coastal systems. Tierney and Bruneau (2007) suggested measuring resilience based on observing that resilient systems reduce the probabilities of failure and enhance recovery, and therefore, resilience can be measured by the performance of an infrastructure system after an external shock including the time it takes to return to initial level of performance. They illustrated the concept as shown in Figure 7 calling it the resilience triangle. Attoh-Okine et al. (2009) used several potential paths of infrastructure performance during normal operation and cases of unexpected events (e.g., a path demonstrating 
sudden failure as shown in Figure 7; a path demonstrating decrease in service life; and a path for the normal operation of the system).

Figure 7. The resilience properties and triangle.

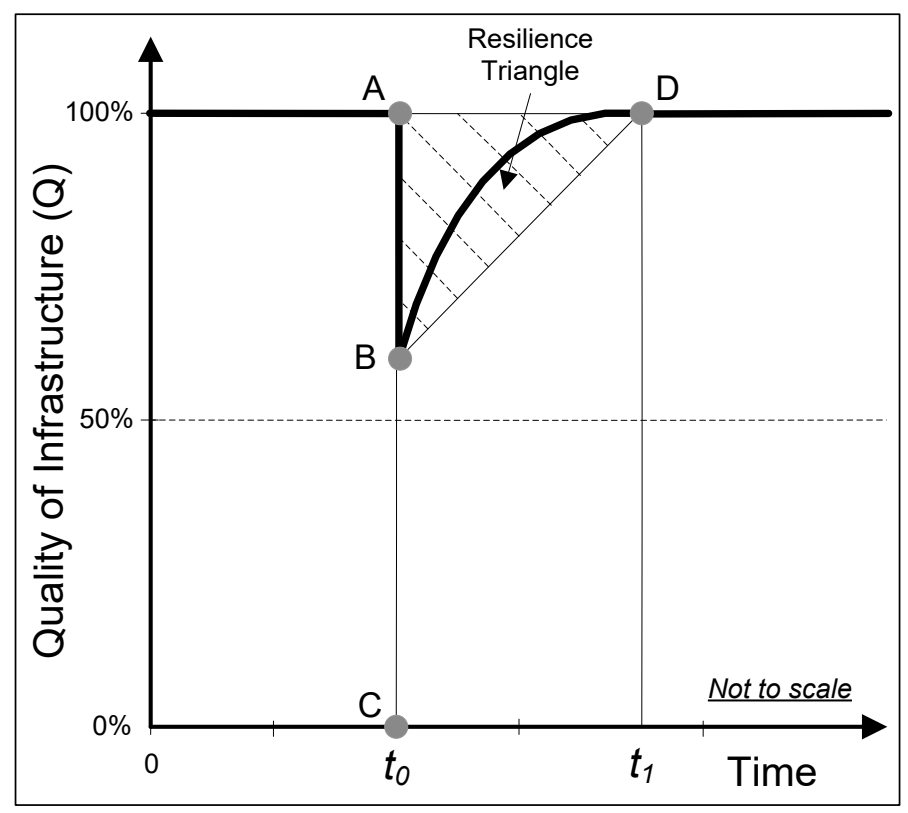

Attoh-Okine et al. (2009) used the concept of resilience as illustrated in Figure 7 to define a resilience index as follows:

$$
\text { Resilience }=\frac{\int_{t_{0}}^{t_{1}} Q(t) d t}{100\left(t_{0}-t_{1}\right)}
$$

where $Q$ is the infrastructure quality, or the performance of a system, $t_{0}$ is the time of incident or disturbance occurrence, and $t_{1}$ is the time to full recovery. According to this model, the units of resilience are performance per unit time, where performance can be measured in percent according to Equation 3.1. The earthquake community used Equation 3.1 with a suggested framework of resilience called the four "Rs" defined as follows (Tierney and Bruneau 2007):

1. Robustness as the ability of the system and system elements to withstand external shocks without significant loss of performance.

2. Redundancy as the extent to which the system and other elements satisfy and sustain functional requirements in the event of disturbance. 
3. Resourcefulness as the ability to diagnose and prioritize problems and to initiate solutions by identifying and monitoring all resources, including economic, technical, and social information.

4. Rapidity as the ability to recover and contain losses and avoid future disruptions.

These properties are defined in Table 7 with reference to Figure 7 based on models provided by Shinozuka et al. (2004). Other models are available as described in subsequent paragraphs.

Table 7. Definition of resilience properties.

\begin{tabular}{|l|l|l|l|}
\hline & $\begin{array}{l}\text { Models } \\
\text { (Points A, B, C, and D per } \\
\text { Figure 7) }\end{array}$ & Units & \\
\hline Robustness & Robustness = B - C & Percentage & (3.2) \\
\hline Redundancy & Not defined & & \\
\hline Resourcefulness & Not defined & $\begin{array}{l}\text { Average } \\
\text { recovery rate } \\
\text { in percentage } \\
\text { per time }\end{array}$ & (3.3) \\
\hline Rapidity & Rapidity $=\frac{A-B}{t_{0}-t_{1}}$ & &
\end{tabular}

$\mathrm{Li}$ and Lence (2007) refined the resilience index developed by Hashimoto et al. (1982) by using the performance ratio over two different time periods. Omer et al. (2009) measure resilience for internet infrastructure systems as the ratio of the difference in information transmission before (initial), and after an event divided by the initial information transmission. Attoh-Okine et al. (2009) also provided formulation of a resilience index of urban infrastructure using belief functions. McGill and Ayyub (2009) related resilience concepts to regional capabilities performance assessment for human-caused hazards in homeland security.

Gilbert (2010) provides extensive coverage of and mathematical models for recovery after a storm in the context of a disaster cycle consisting of response, recovery, mitigation and preparedness. He includes in his discussion partial recovery and full recovery including instant urban renewal of population recovery, physical infrastructure, economy, social networks, government services, and environments. He also develops simulation models of recovery and provides validation examples (Miles 
and Chang [2003] for the Kobe Earthquake). Generally, the recovery trends shown have decreasing slopes as shown in Figure 7.

Bonstrom and Corotis (2014) provide a first-order reliability approach to quantify and improve building portfolio resilience. The approach builds on the concept of Figure 7 affecting the relative quality at point B, the shape of the resilience triangle as represented by the nonlinear curve connecting $\mathrm{B}$ and $\mathrm{D}$, and the position of point $\mathrm{D}$ at $t_{1}$. It also includes a fundamental uncertainty treatment with a reliability framework.

Fox-Lent et al. (2015) developed a matrix approach for measuring and communicating community resilience. Rosati et al. (2015) developed resilience metrics using the four concepts of resilience: prepare, resist, recover, and adapt. Linkov et al. (2013) suggested the resilience matrix (Figure 8) that maps system domains across an event management cycle of resilience functions. Cells in this matrix provide guidelines for resilience metrics that need to be developed and combined to measure overall system resilience.

Figure 8. The resilience matrix (Linkov et al. 2013).

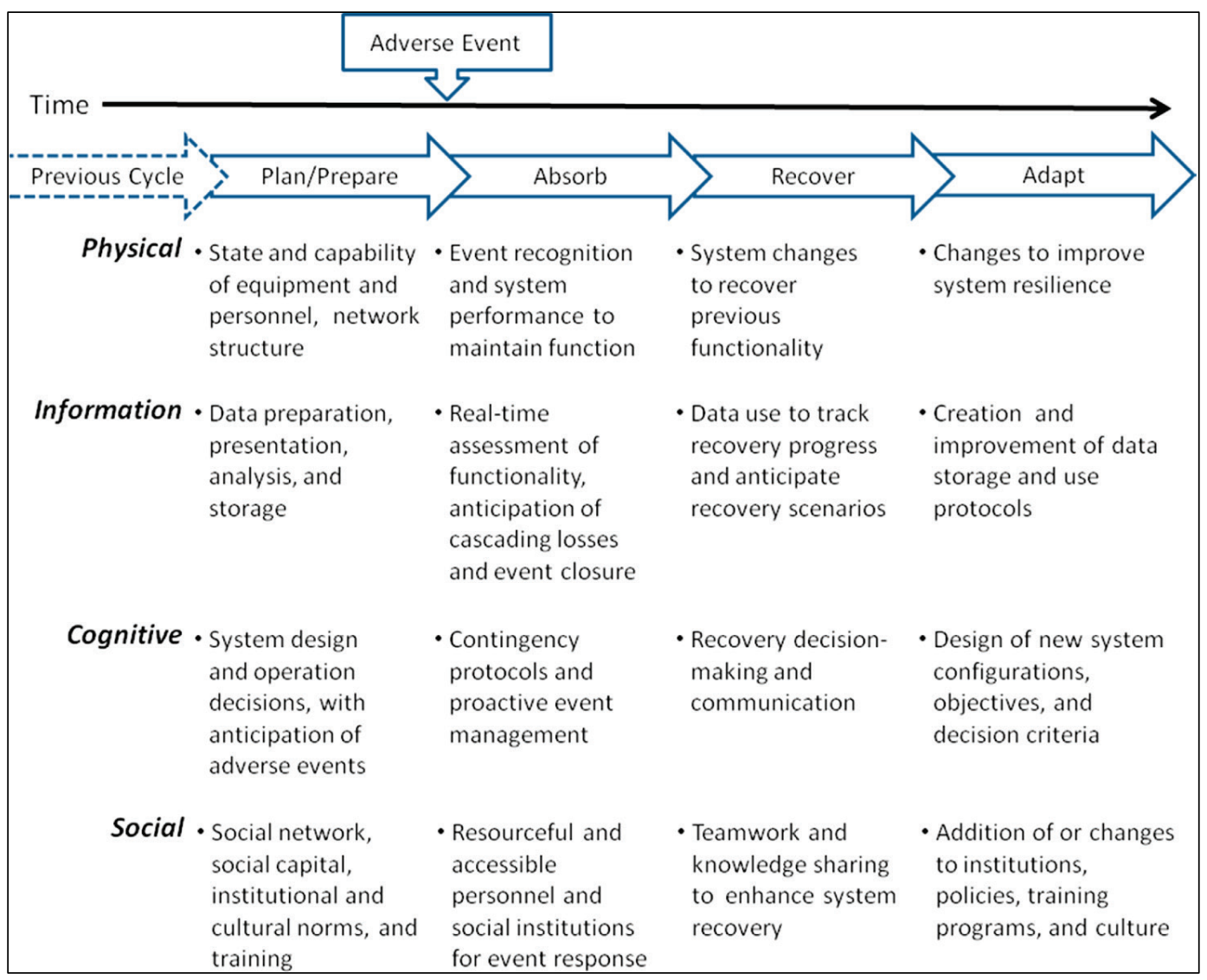


Ayyub (2014a) suggested resilience metrics that are consistent with the resilience definition provided earlier (as persistence of the system's functions and performances under uncertainty in the face of disturbances) and that meet the requirements imposed on such a definition. The definition captures the details of resilience concept of Figure 7 at both the quality and time axes. Ayyub (2014a) used Figure 9 to provide a schematic representation of a system performance $(Q)$ with aging effects and an incident occurrence with a rate $(\lambda)$ according to a Poisson process. At time $t$, it might lead to degraded performance called failure, of a duration $\Delta T_{f}$. The failure event concludes at time $t_{f}$.

Figure 9. Proposed definitions of resilience metrics (adapted from Ayyub 2014a).

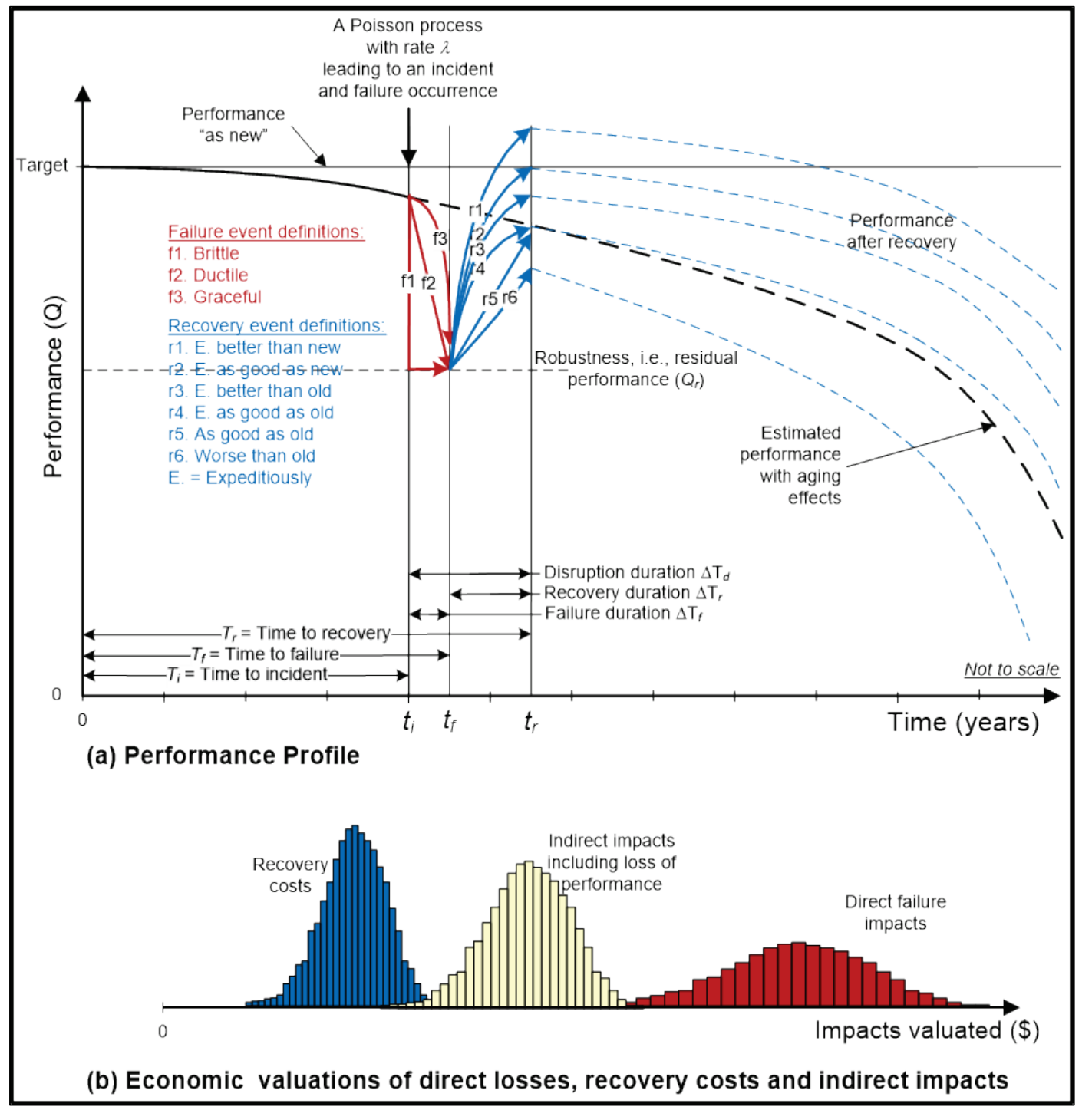


The failure event is followed by a recovery event with a duration $\Delta T_{r}$. The recovery event concludes at time $t_{r}$. The total disruption $(D)$ has a duration of $\Delta T_{d}=\Delta T_{f}+\Delta T_{r}$. The figure shows for illustration purposes three failure events: (1) brittle ( $f 1),(2)$ ductile ( $\left.f_{2}\right)$, and (3) graceful (f3), and six recovery events: (1) expeditious recovery to better-than-new ( $r 1),(2)$ expeditious recovery to as-good-as-new $(r 2)$, (3) expeditious recovery to better-than-old ( $r 3$ ), (4) expeditious recovery to as-good-as-old ( $r 4),(5)$ recovery to as-good-as-old ( $r 5$ ), and (6) recovery to worse-than-old ( $r 6)$. These events define various rates of change of performance of the system. The figure also shows the aging performance trajectory and the estimated trajectory after recovery. The proposed model to measure resilience is the following:

$$
\operatorname{Resilience}\left(R_{e}\right)=\frac{T_{i}+F \Delta T_{f}+R \Delta T_{r}}{T_{i}+\Delta T_{f}+\Delta T_{r}}
$$

where for any failure event $(f)$ as illustrated in Figure 9, the corresponding failure profile $F$ is measured as follows:

$$
\text { Failure }(F)=\frac{\int_{t_{i}}^{t_{f}} f d t}{\int_{t_{i}}^{t_{f}} Q d t}
$$

Similarly, for any recovery event $(r)$ as illustrated in Figure 9, the corresponding recovery profile $R$ is measured as follows:

$$
\operatorname{Recovery}(R)=\frac{\int_{t_{f}}^{t_{r}} r d t}{\int_{t_{f}}^{t_{r}} Q d t}
$$

The failure-profile value $(F)$ can be considered as a measure of robustness and redundancy and is proposed to address the notion offered by Equation 3.2 whereas the recovery-profile value $(R)$ can be considered as a measure of resourcefulness and rapidity and is proposed to address the notion offered by Equation 3.3. The time to failure $\left(T_{f}\right)$ can be characterized by its probability density function computed as follows: 


$$
-\frac{d}{d t} \int_{s=0}^{\infty} \exp \left[-\lambda t\left(1-\frac{1}{t} \int_{\tau=0}^{t} F_{L}(\alpha(\tau) s) d \tau\right)\right] f_{S_{0}}(s) d s
$$

where $Q$ is defined as the system's performance in terms of its strength $(S)$ minus the corresponding load effect $(L)$ in consistent units (i.e., $Q=S-L$. Both $L$ and $S$ are treated as random variables, with $F_{L}=$ the cumulative probability distribution function of $L$, and $f_{S}=$ the probability density function of $S$ ). The aging effects are considered in this model by the term $\alpha(t)$ representing a degradation mechanism as a function of time $t$. Note that the term $\alpha(t)$ can also represent improvement to the system.

Equation 3.7 is based on a Poisson process with an incident occurrence, such as loading, rate of $\lambda$, and is based on Ellingwood and Mori (1993). The probability density function of $T_{f}$ as shown in Equation 3.7 is the negative of the derivative of the reliability function. The times $T_{i}, T_{f}$, and $T_{r}$ are random variables as shown in Figure 9 and are related to durations as follows:

$$
\begin{gathered}
\Delta T_{f}=T_{f}-T_{i} \\
\Delta T_{r}=T_{r}-T_{f}
\end{gathered}
$$

The disruption duration is given by

$$
\Delta T_{d}=\Delta T_{f}+\Delta T_{r}
$$

The model of Equation 3.4 for measuring resilience meets the set of requirements previously described (Ayyub 2014a).

Figure 9 also shows the associated costs including losses, recovery cost, and indirect costs. These losses and costs should be based on total economic valuations using anthropocentric considerations. Ayyub (2014a) provides background information on these concepts. Resilience metrics should lend themselves for total economic valuation, but the development of frameworks for economic analysis is beyond the scope of this report.

Primary limitations of available resilience quantification methods can be classified as (1) inappropriately structured and (2) complex.

The model of Equation 3.1 according to Table 7 and Figure 7 measures resilience in the units of performance per unit time. It focuses on the 
recovery slope and does not account for the rates of stressors, the probability of failure as a result of a stressor, the failure profile, and recovering to states other than as-good-as-new. Such models do not account for failure rates and probabilities. Therefore, they do not meet the resilience definition by not accounting for the ability of a system to withstand a stressor.

Although the model of Equations 3.4 to 3.10 and Figure 9 offer a comprehensive capture of the resilience attributes according to the resilience definition, it is complex and might be impractical. The limitations of this model are addressed through the development of simplified, practical metrics. The intended users of such simplified metrics are practitioners including engineers, city planners, decision makers, analysts, and policy makers.

\subsection{Practical resilience metrics}

This section offers practical metrics that are consistent with recently suggested rigorous ones (e.g., Equations 3.4 to 3.10). Such metrics would provide a sound basis for the development of effective decision-making tools for multi-hazard environments. Achieving this objective requires simplifying the concepts presented in Figure 9 and Equation 3.4 while maintaining intent, comprehensiveness, and accuracy. The accuracy level should be commensurate with the decisions to be informed by setting appropriate resolution levels in constructing a system's model.

Consider a fundamental case having a performance level that would be maintained and sustained over time (i.e., no aging effects, with a brittle failure profile) (i.e., f1, in Figure 9). Also, assume as-good-as-old recovery, where old is the state immediately prior to failure (i.e., r5 in Figure 9). This fundamental case is shown in Figure 10. Additionally, the following assumptions are made: (1) a planning horizon $(t),(2)$ Poisson process of stressors with a rate $(\lambda)$ as shown in Figure 11 (Ayyub 2015), (3) the planning horizon related to the stressor rate as $t=1 / \lambda$, (4) failure probability $(p)$ due to a stressor, and (5) independent failures. Note that the stressors have varied intensities (see Figure 11), and not all stressors fail the system and disrupt the system's performance. The failure probability is denoted as $p$. Two fundamental cases are presented in this section: the case of linear recovery and the case of step recovery. 
Figure 10. Fundamental resilience Case I of linear recovery.

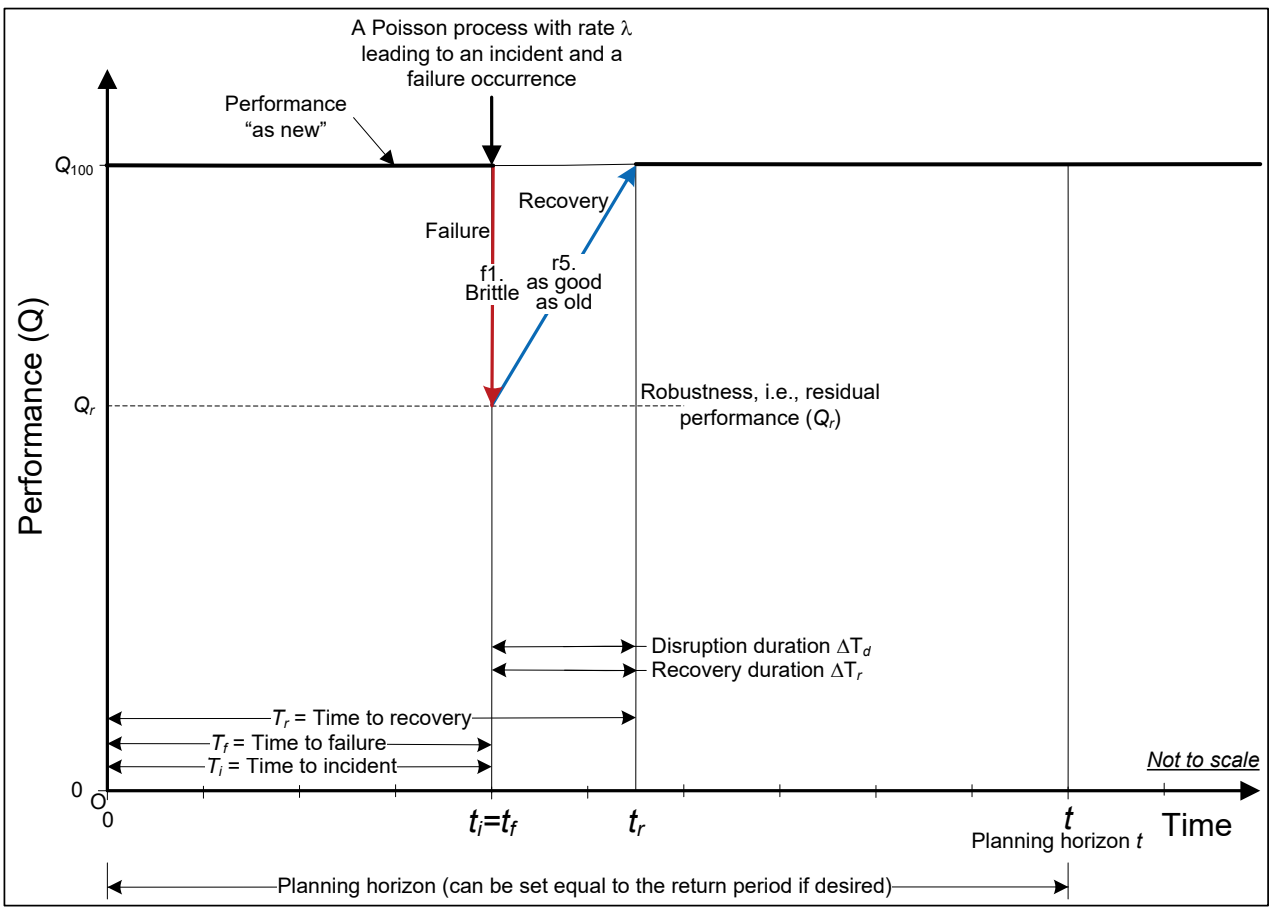

Figure 11. A Poisson process of a stressor with varied intensity.

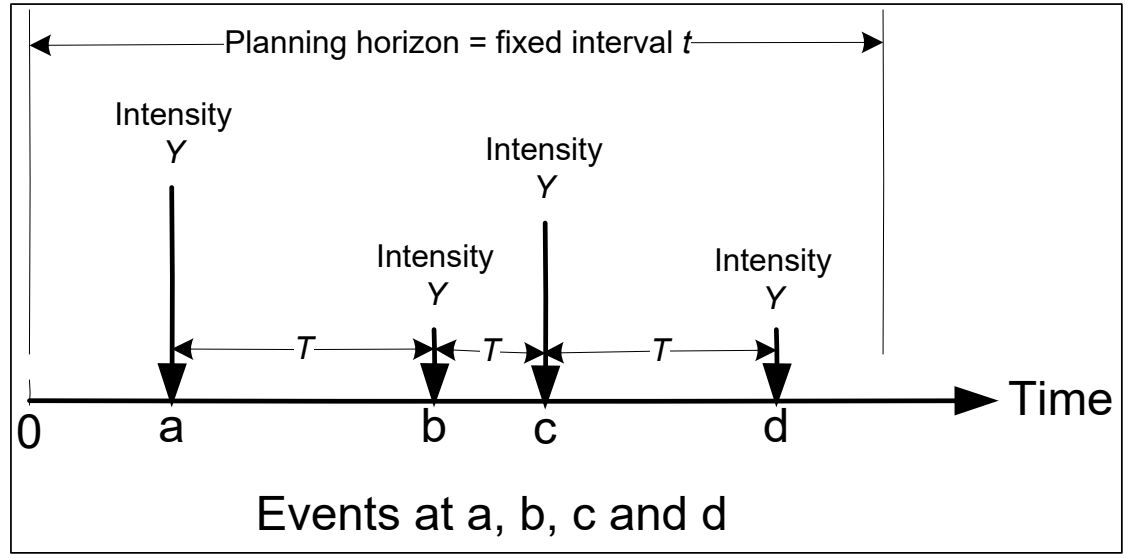

For the fundamental case of a linear recovery as shown in Figure 10, the resilience metric of Equation 3.4 for one failure-causing event is basically the ratio of two areas according to this figure (i.e., the rectangular area tQ100, divided by the $\mathrm{tQ100}$ without the triangle representing the degraded performance of the system). The triangle has the sides of brittle failure and linear recovery. For a linear recovery path $(r)$, it can be expressed as follows for one failure-inducing event:

$$
\text { Linear recovery: Resilience per failure }\left(R_{f}\right)=1-\frac{\left(t_{r}-t_{i}\right)\left(Q_{100}-Q_{r}\right)}{2 Q_{100} t}
$$


For analytical and computational convenience, the concept of nonresilience can be introduced and defined as follows:

$$
\text { Linear recovery: Non-resilience per failure }\left(\bar{R}_{f}\right)=\frac{\left(t_{r}-t_{i}\right)\left(Q_{100}-Q_{r}\right)}{2 Q_{100} t}
$$

The relationship between $R_{f}$ and $\bar{R}_{f}$ is

$$
\bar{R}_{f}=1-R_{f}
$$

Equations 3.11 and 3.12 can be generalized to account for the potential of multiple occurrences of failure-inducing events $x$ and their associated probabilities as follows:

$$
\text { Resilience }\left(R_{e}\right)=1-\sum_{x=1}^{\infty}\left(\exp (-\lambda t) \frac{(\lambda t)^{x}}{x !} p^{x} \bar{R}_{f}^{x}\right)
$$

The following infinite series can be used to reduce Equation 3.14:

$$
\exp (\lambda t)=1+(\lambda t)+\frac{(\lambda t)^{2}}{2 !}+\frac{(\lambda t)^{3}}{3 !}+\cdots
$$

Equation 3.14 is reduced to

$$
\text { Resilience }\left(R_{e}\right)=1-\exp (-\lambda t)\left(\exp \left(\lambda t p \bar{R}_{f}\right)-1\right)
$$

Equation 3.16 can be reduced further to the following practical form:

$$
\text { Resilience }\left(R_{e}\right)=1-\exp \left(-\lambda t\left(1-p \bar{R}_{f}\right)\right)+\exp (-\lambda t)
$$

For the fundamental case of step recovery as shown in Figure 12a, the resilience metric of Equation 3.4 for one failure-causing event is again the ratio of two areas according to this figure (i.e., the rectangular area $t Q_{100}$, divided by the $t Q_{100}$ without the rectangle representing the loss of functionality of the system). It can be expressed as follows for one failureinducing event: 
Step recovery: Resilience per failure $\left(R_{f}\right)=1-\frac{\left(t_{r}-t_{i}\right)\left(Q_{100}-Q_{r}\right)}{Q_{100} t}$

Figure 12. Fundamental resilience Case II of one-step (a) and two-step (b) recovery.

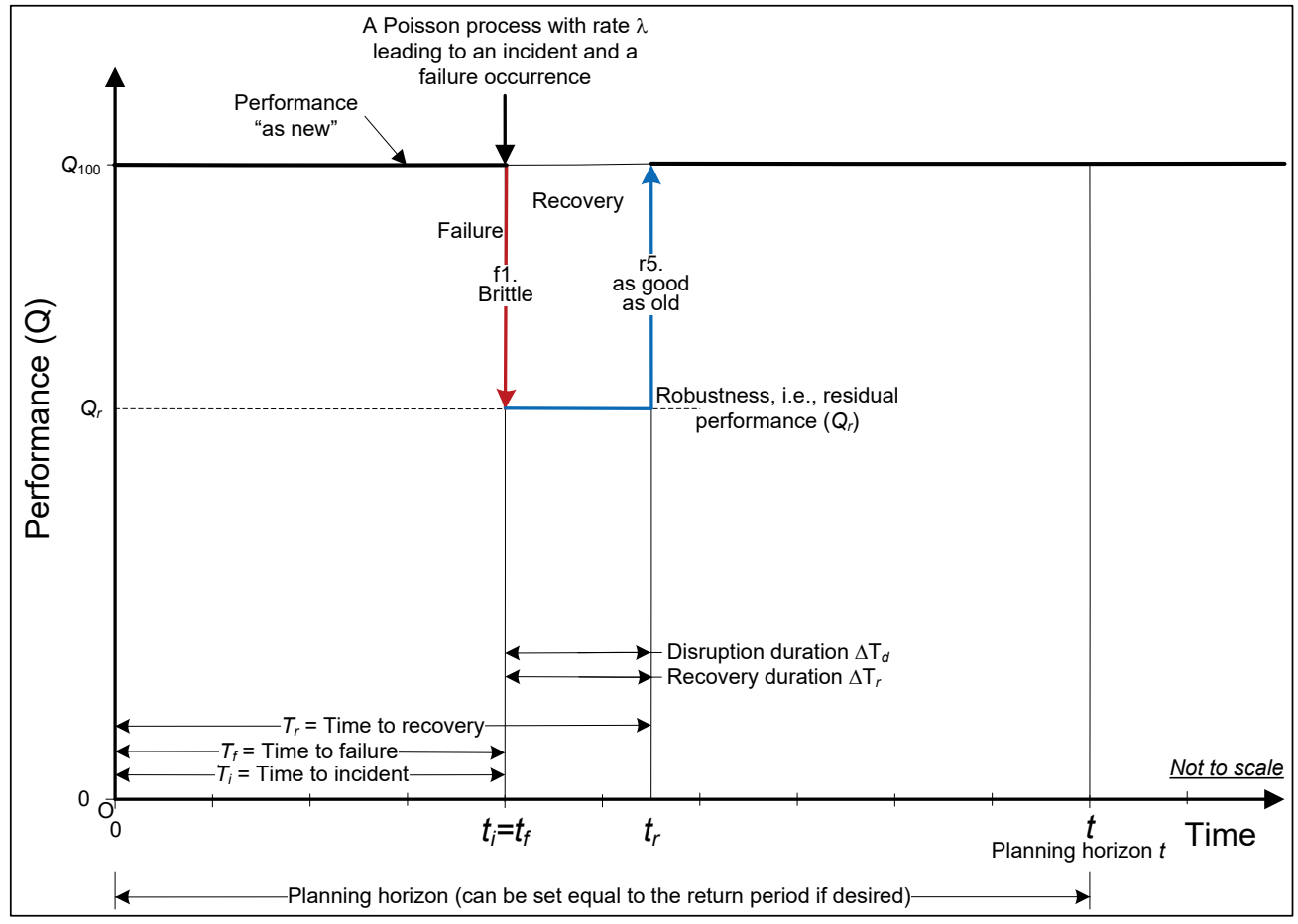

(a) One-step recovery.

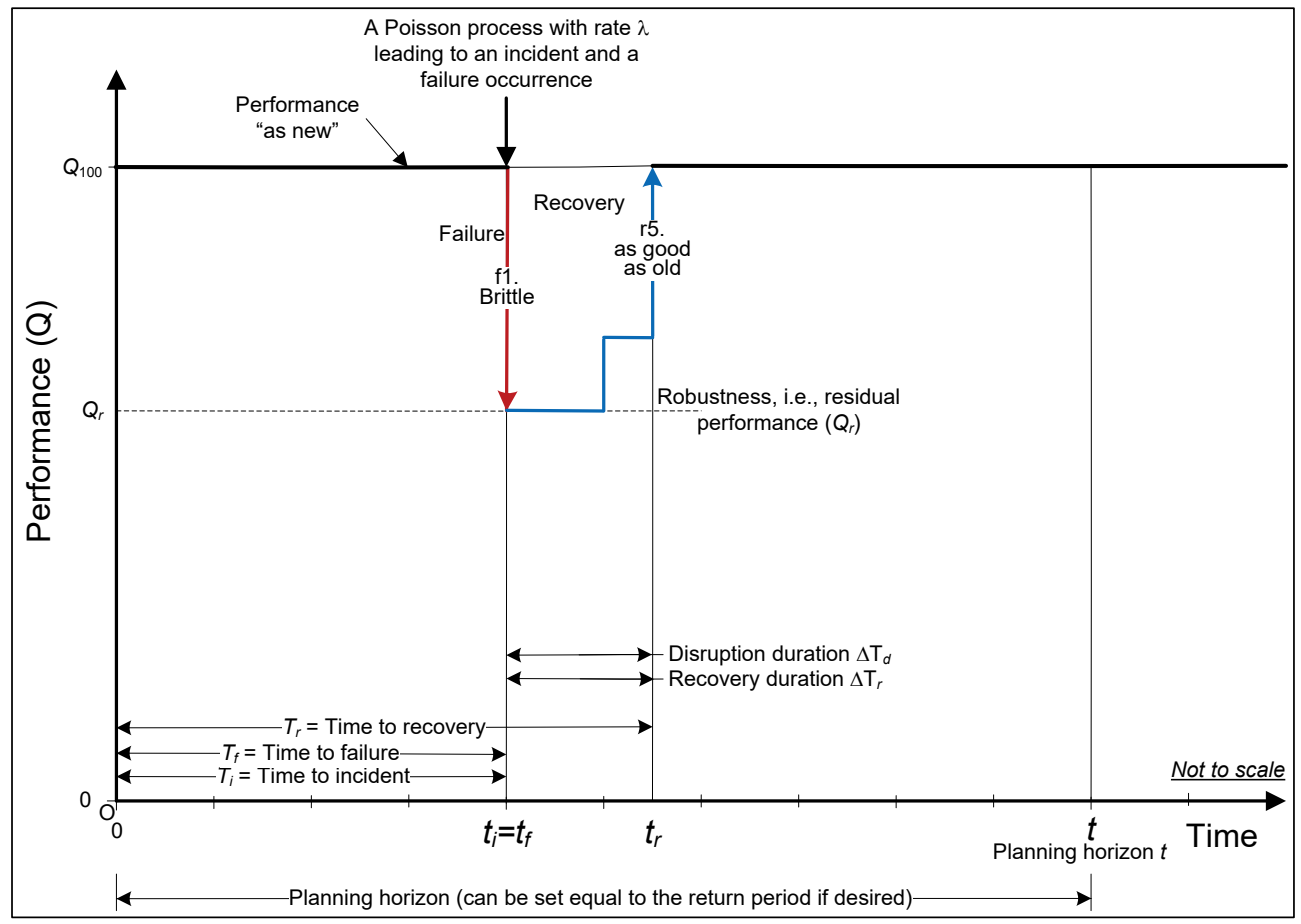

(b) Two-step recovery. 
For analytical and computational convenience, the concept of nonresilience can be introduced and defined as follows:

$$
\text { Step recovery: Non-resilience per failure }\left(\bar{R}_{f}\right)=\frac{\left(t_{r}-t_{i}\right)\left(Q_{100}-Q_{r}\right)}{Q_{100} t}
$$

The relationship between $R_{f}$ and $\bar{R}_{f}$ is provided in Equation 3.13.

Equation 3.17 can be used to compute the resilience. This fundamental case can be extended easily to a generalized case of multiple steps where recovery is achieved by bringing into operation portions of a system while remaining portions are being restored. A two-step case is shown in Figure 12b.

Equation 3.17 offers the simplicity and practicality desired for systems with time invariant performance and accounts for the following:

- rate of events (i.e., the rate $\lambda$, of a Poisson process)

- probability of failure $(p)$ given a stressor (i.e., inherent strength of the system)

- capacity of the system $\left(Q_{100}\right)$

- robustness of the system $\left(Q_{r}\right)$

- brittle failure and linear or step recovery to as-good-as-old profiles

- non-resilience associated with the occurrence of a failure-inducing event

- planning horizon $t$

- stressor time as a result of failure-inducing event.

For cases where the planning horizon $(t)$ is equal to the return period $(1 / \lambda)$, Equation 3.17 can be reduced to the following special case:

$$
\text { Resilience }\left(R_{e}\right)=1-\exp \left(-\left(1-p \bar{R}_{f}\right)\right)+\exp (-1)
$$

Ayyub (2015) provides illustrative examples based on these models. 


\section{Recovery Profiles and Models}

\subsection{Recovery of societies}

The Nobel Laureate Gary Becker believes in the accuracy of the outlook of the great nineteenth-century English economist and philosopher John Stuart Mill, who marveled at the "great rapidity with which countries recover from a state of devastation, the disappearance in a short time of all traces of mischief done by earthquakes, floods, hurricanes, and the ravages of war." Both natural and human-caused disasters during the subsequent century-and-a-half are generally on the side of Mill's claim. Becker et al. (2005) present these examples:

- The September 11, 2001, coordinated attacks in New York City and Washington, DC, resulted in 2,996 deaths and at least $\$ 10$ billion in property and infrastructure damage. These attacks had a slight overall impact on the course of Gross Domestic Product (GDP) and employment in the United States, although some industries and New York City were affected for several years.

- The Kobe earthquake of 1995 resulted in 6,000 deaths and the destruction of more than 100,00o homes. The economic recovery not only of Japan but also of Kobe was rapid.

- The flu pandemic of 1918 to 1919 resulted in approximately 30 million deaths worldwide without having a major impact on the world's economy.

- The 2004 Indian Ocean earthquake and tsunami resulted in 227,898 deaths and approximately 1.5 million people displaced in 15 countries; however, the Asian stock markets did not change much.

General conclusions cannot be made based on these examples due to several factors including (1) the wealth of a nation, (2) the extent and sophistication of insurance coverage, (3) education and earning levels of populations, (4) access to healthcare and emergency response national and international channels, (5) governance, and (6) social and cultural considerations. Interconnectedness and moral risk effects add other levels of complexity that are difficult to address.

Among other factors, the ability of a society to recover after a disaster mainly depends on whether its population size has been significantly reduced by death or displacement. With the same skill and knowledge they 
possessed prior to the disaster, with their land and primary improvements undestroyed, the society has nearly all the requisites for their former amount of production. This ability can be associated as an attribute of living systems, and the society being alive (i.e., vis medicatrix naturae literally means "the healing power of nature" [Becker et al. 2005]). The recovery trajectory is greatly affected by the state of the post-disasters landscape, infrastructure availability, and population size. This paper assumes that in a post-disaster landscape the population and resources remain the same but that infrastructure will need to be repaired to a preevent state or better as discussed in subsequent sections.

\subsection{Recovery models and classification}

Cimellaro et al. (2010), Chang and Shinozuka (2004), and Kafali and Grigoriu (2005) suggested the use of linear, trigonometric, or exponential models for recovery profiles. These models offer the flexibility needed to accommodate various cases, however, might not be supported by data. The complexity in the functional forms of recovery profiles might not be justifiable by empirical evidence and in the common presence of significant uncertainties. The two cases presented in Figures 10 and 11 (i.e., a triangular disruption or a linear model and a rectangular disruption or a step function) are recommended for now until data are collected and classifications made to justify other forms. The case studies presented at the end of this section offer some recovery features that might help to select appropriate profiles.

Figure 9 shows several recovery profiles for the purpose of illustration (Ayyub 2014a). Several recovery types are listed as follows:

- Expeditious recovery to a performance level that is better-than-new (r1)

- Expeditious recovery to a performance level that is as-good-as-new (r2)

- Expeditious recovery to a performance level that is better-than-old (r3)

- Expeditious recovery to a performance level that is as-good-as-old ( $\mathrm{r} 4$ )

- Recovery to a performance level that is as-good-as-old ( $\mathrm{r}_{5}$ )

- Recovery to a performance level that is worse-than-old (r6).

Figure 9 also shows failure profiles that are in common use.

The type of systems may offer a useful basis for classification, such as the following: 
- Society or community recovery

- Economic recovery

- Regional recovery

- Country recovery

- Corporate recovery

- Market recovery

- Supply-chain recovery

- Infrastructure system recovery, such as electric power recovery

- Environmental recovery

- Earth recovery

- Individual health or public health recovery

- Relationship recovery.

The recovery level, spatial scale, and time might have utility as a basis for classification, such as the following:

- By level

- No recovery

- Diminished recovery

- Superior recovery

- By spatial scale

○ Uniform versus non-uniform

- Spatially random

○ Spatially trending

- By time

- Linear versus nonlinear

$\circ$ Time lagging

- Gradual versus abrupt

- Step function

- Asymptotic

- By recovery agent
- Human
- Nature

- Combinations of level, space and temporal cases 


\subsection{Case studies}

\subsubsection{Case Study I: Hurricane Katrina and New Orleans (2005)}

Hurricane Katrina (August 23 to 31, 2005) was an extraordinary act of nature and perhaps the most destructive natural disaster in American history, creating a human tragedy and laying waste to $82,000 \mathrm{mi}^{2}$ $\left(212,000 \mathrm{~km}^{2}\right)$ of land, an area the size of the United Kingdom (Barras 2007). In Louisiana and Mississippi, the storm surge obliterated coastal communities and left thousands destitute. One of the primary contributors to the flooding of New Orleans was the failures of levees and floodwalls that make up the hurricane protection system. The utilization of engineered systems leads to risks that result from humans using technology in an attempt to gain benefits, such as control of naturally occurring conditions.

According to Federal Emergency Management Agency (FEMA), the total damage from Katrina was $\$ 108$ billion (in 2005 U.S. dollars). The direct and indirect fatalities stand at 1,833 (FEMA 2016. It is estimated that the primary causes of death in Louisiana were drowning (40\%), injury and trauma (25\%), and heart conditions that proved fatal under stress (11\%). Also, it is estimated that approximately 50\% of the fatalities in Louisiana were people over the age of 74. Payments to fulfill insurance claims totaled an estimated $\$ 41.1$ billion from private insurers and $\$ 16.1$ billion from the National Flood Insurance Program. During Katrina, approximately 70\% of New Orleans housing was damaged (CNN 2016) and more than one million people in the Gulf region were displaced. In the years after Katrina, the federal government has spent $\$ 120.5$ billion on the Gulf Region to repair storm damage. The hurricane destroyed levees that led to flooding $80 \%$ of the city and reducing its population by over 50\% comparing April 2000 to July 2006. By 2012, the population increased to 369,250.

The Bureau of Economic Analysis (BEA) publishes economic statistics data at http://www.bea.gov/data used to construct Figure 13. The figure shows the GDP for all industries in the United States, and the GDP of all industries in New Orleans indexed to the year 2001. Estimating recovery time for the city from Figure 13 is not easy because of the multidimensionality of recovery. The recovery period can be estimated approximately to be 8 years based on GDP returning to comparable levels to pre-Katrina, although the population growth has not kept up with the GDP growth. This disparity perhaps is attributable to changes in the composition of the industries, and population skill levels and income. The 
primary conclusion is the recovery profile in terms of GDP being almost linear and similar to Figure 13.

Figure 13. Economic recovery of New Orleans.

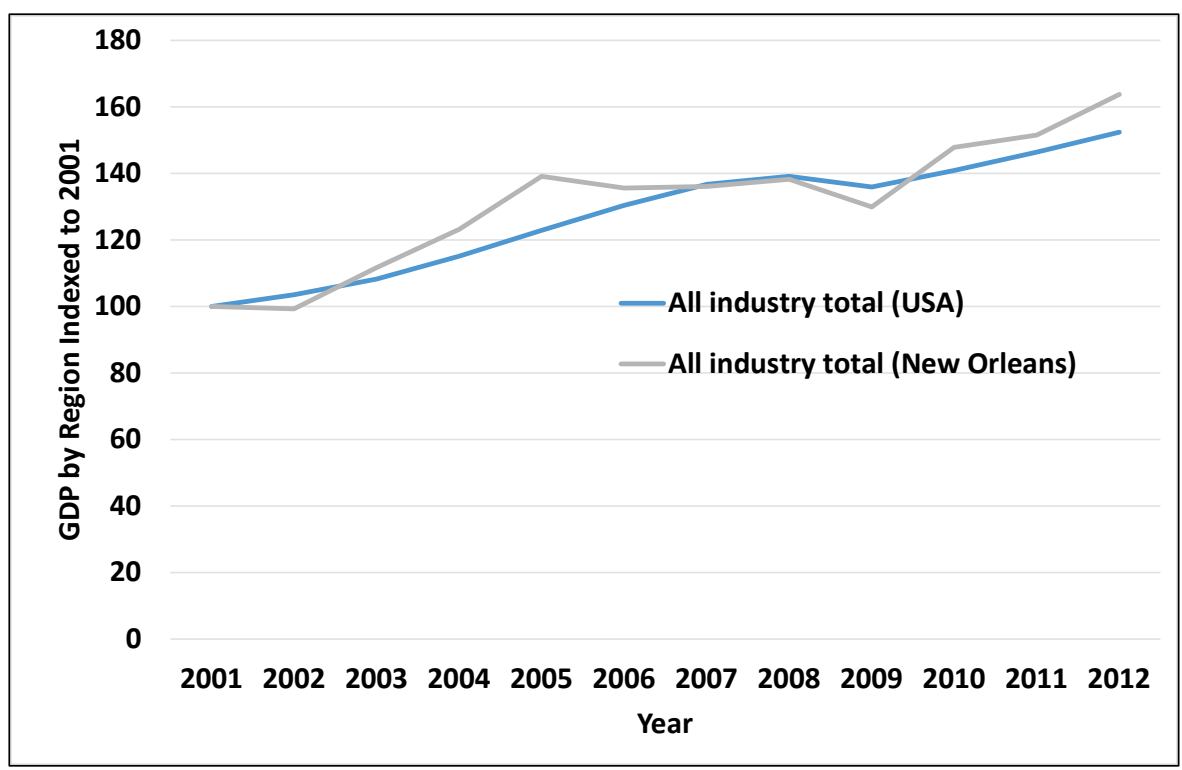

\subsubsection{Case Study II: Highway I-35W Mississippi River Bridge collapse (2007)}

An 8-lane, steel truss arch bridge carrying Interstate 35W across the Saint Anthony Falls of the Mississippi River in Minneapolis, Minnesota, collapsed during rush hour on 1 August 2007, resulting in 13 deaths and 145 injuries. The bridge was carrying average daily traffic of approximately 140,000 vehicles. The National Transportation Safety Board investigated and identified a design flaw as the likely cause of collapse. A replacement bridge was fast tracked through planning, design, and construction and opened to traffic on 13 September 2008. The recovery time in this case was approximately 1 year. The bridge robustness in this case is $0 \%$, and the recovery profile is as provided in Figure 12a.

\subsubsection{Case Study III: The World Trade Center collapse (2001)}

Reconstruction of the World Trade Center after the 11 September 2001 destructive attack in New York City was deferred until 2006 due to disputes between the Port Authority and the developer. One World Trade Center opened 13 years later to tenants on 3 November 2014. Construction of additional towers is underway. A recovery has not been achieved yet. The anticipated recovery profile is a multi-step recovery as provided in Figure 12b. 


\section{Decision Analysis for Enhancing Resilience}

The concepts and metrics provided in this report are intended to inform decision- and policy-making practices. They are consistent with riskinformed decision analysis methods and lend themselves to economic valuation.

The economics of resilience can be based on the potential savings in direct and indirect losses and cost of recovery as illustrated in Figure 9.

Alternatives for enhancing resilience that can reduce these potential losses can be analyzed using models for benefit-cost analysis, where the benefit $(B)$ is the potential savings in losses and recovery costs due to the implementation of an alternative and the cost $(C)$ is the cost of the alternative. The benefit and costs are treated as random variables (Ayyub 2014b). Assuming $B$ and $C$ to be normally distributed, a benefit-cost index $\left(\beta_{B} / C\right)$ can be defined as follows:

$$
\beta_{B / C}=\frac{\mu_{B}-\mu_{C}}{\sqrt{\sigma_{B}^{2}+\sigma_{C}^{2}}}
$$

where $\mu$ and $\sigma$ are the mean and standard deviation. In the case of lognormally distributed $B$ and $C$, the benefit-cost index $\left(\beta_{B / C}\right)$ can be computed as follows:

$$
\beta_{B / C}=\frac{\ln \left(\frac{\mu_{B}}{\mu_{C}} \sqrt{\frac{\delta_{C}^{2}+1}{\delta_{B}^{2}+1}}\right)}{\sqrt{\ln \left[\left(\delta_{B}^{2}+1\right)\left(\delta_{C}^{2}+1\right)\right]}}
$$

where $\delta$ is the coefficient of variation. In the case of mixed distributions or cases involving basic random variables of $B$ and $C$, other reliability methods can be used as described by Ayyub (2014b). The probability of cost exceeding benefit can be computed as follows:

$$
P_{f, B / C}=P(C>B)=1-\Phi(\beta)
$$

where $\Phi$ is the standard normal cumulative distribution function. 


\section{Summary and Future Work}

\subsection{Summary}

This report provides a resilience definition that meets a set of requirements with clear relationships to metrics of the relevant abstract notions of reliability and risk. The report provides metrics that are practical and simplified while capturing the attribute set in the resilience definition.

Coastal infrastructure includes features designed for particular purposes relating to storm risk management and meeting other utilities. The performances of these features and ways to measure them are foundational in nature for quantifying resilience. Features are classified in this report and performances illustrated for several cases. Recovery models with case studies and illustrative examples are also provided. Next steps are defined in this chapter.

Massive savings could be realized by enhancing the resilience of coastal infrastructure systems, including buildings, infrastructure, network, and communities through risk reduction and expeditious recovery. This report provides key foundational elements towards realizing these savings.

\subsection{Future work}

This chapter ends with five research tracks for future work. The research tracks are on metrics related to costal features in the case of multiple events with coastal nourishment, resilience aggregation, examination of decision strategies and alternatives, the relationship between resilience and sustainability, and asset management.

\subsubsection{Coastal features: Multiple events, erosion, nourishment, and failure}

The coast, as a very dynamic environment with coastal shorelines that include beaches, dunes, and banks, changes constantly in response to wind, waves, tides, and other factors such as seasonal variation, sea level rise, and human alterations to the system. Storms that are stochastic in nature stress the system at a particular moment. These storm events vary in intensity and could lead to significant erosion or failure by breaching dunes or banks. Figure 14 illustrates the natural erosion and accretion 
processes of artificial dunes or dune enhancements to protect property at risk. These shore stabilizing methods should be designed with multiple goals including erosion reduction, habitat creation, and flood damage reduction. However, artificial dunes and beaches depend on renourishment to provide these services throughout their life cycle (USACE 2013a).

Figure 14. Erosion and accretion processes of built shorelines during storms (USACE 2002).

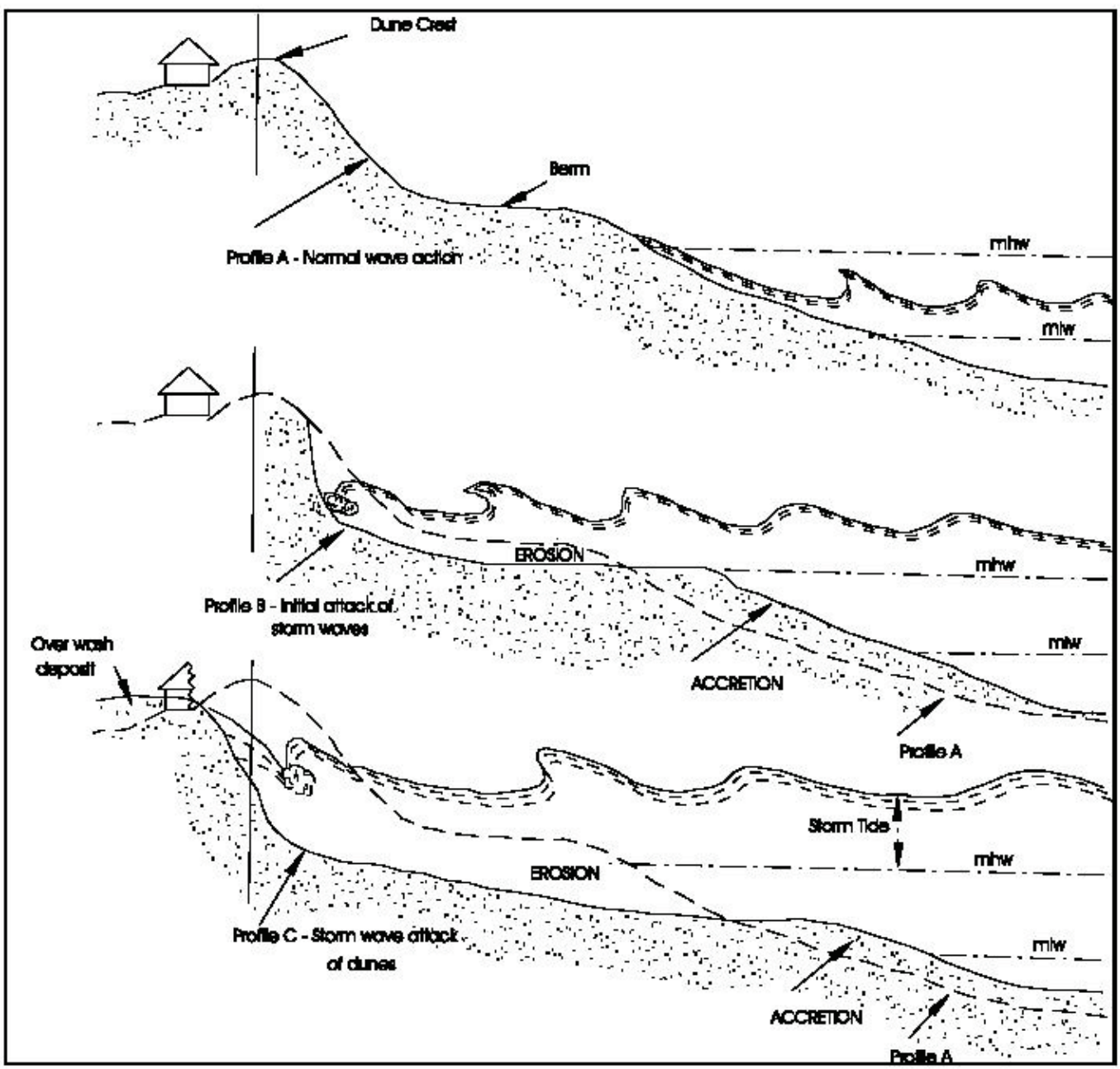

Additional work could focus on selected coastal features and their performance over time, such as dunes, banks, barrier islands, etc. The dunes of Figure 14 are further examined herein for the purpose of illustration. Figure 15 shows the performance schematics of a particular dune segment over time. Several performance attributes could be tracked such as (see also Gravens et al. 2014; Nordstrom 2000, 2009): 
- The minimum or average width of the dune

- The height of the dune

- The seaward slope of the dune

- The coverage area of vegetation used for its stabilization including the type of vegetation and its root system (see, for example, Huang and Yim [2014]).

Figure 15. Performance under multiple events.

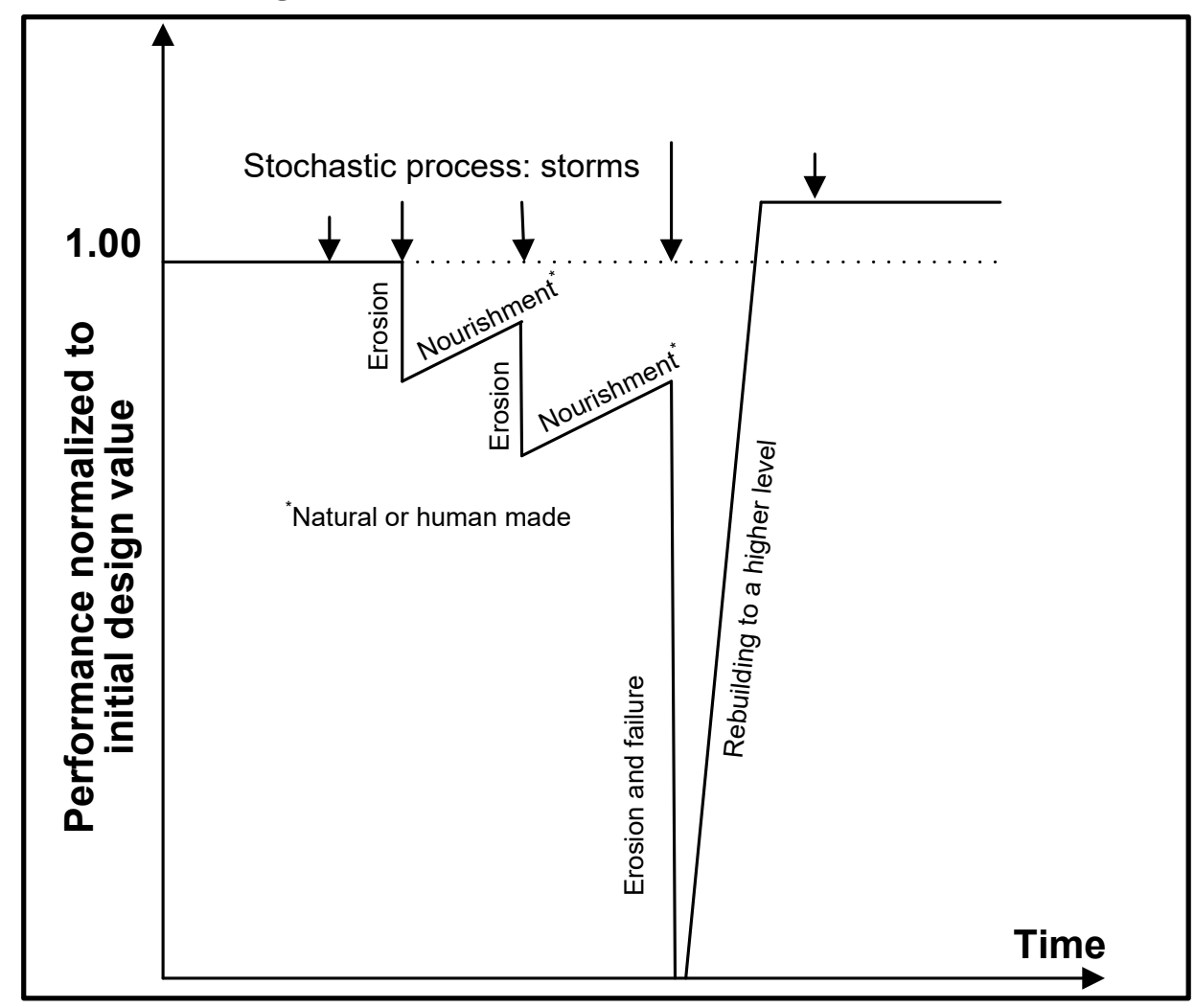

Figure 15 shows the performance based on one of these attributes due to multiple storms represented by a stochastic process, with erosion of varied levels, nourishment that could be natural or human-made, failure, and rebuilding. The performance trend could be used to quantify resilience as described in relation to Figures 9 to 11. Data feeds from satellite images, lidar, cameras, and other sensors could offer the necessary input to quantify, track, and manage resilience within an economic framework that accounts for risks, benefits, and costs of any actions.

\subsubsection{Resilience aggregation}

The development of a system-level model relating components' performances to system performance is beyond the scope of this effort. 
Such a model is domain specific; however, future studies should set metamethodological requirements for the development of such models. Cox (2012) discussed challenges associated with the treatment of system-level resilience, such as communities, and provided illustrations. The MCEER proposed the use of resilience index $\left(R_{i}\right)$ in the range $[0,1]$ for each (the $i^{\text {th }}$ ) quality of service, and an aggregation model for these resilience indices using an independence assumption (MCEER 2010). For examples in the case of two indices, the aggregated index for a system in series with independent components is as follows:

$$
\operatorname{Resilience}\left(R_{12}\right)=\frac{R_{1} R_{2}}{R_{1}+R_{2}-R_{1} \cdot R_{2}}
$$

Figure 16 shows a plot of Equation 6.1 for the case of two identical indices, (i.e., resilience components) for the entire range of values of $R i$. The figure also shows the effect of increasing the number of components from one to ten. The downward intensification is attributed to the independence assumptions. This model does not account for dependencies that are most relevant in the case of coastal infrastructure features. These considerations should be the subject of future pursuits.

System reliability concepts can be considered to develop resilience aggregation methods. Such concepts are provided in many sources on reliability engineering, such as Ayyub (2014b). Separate models might be necessary for the system failure due to component failure, and the system recovery through the recovery of the components. Two sets of interdependencies might affect how a system fails and recovers.

The complexity associated with the resilience of coastal infrastructure as a system of systems is illustrated in Figure 16. 
Figure 16. System resilience aggregate based on two identical resilience components in series, where $n=$ number of components in series (Ayyub 2014a).

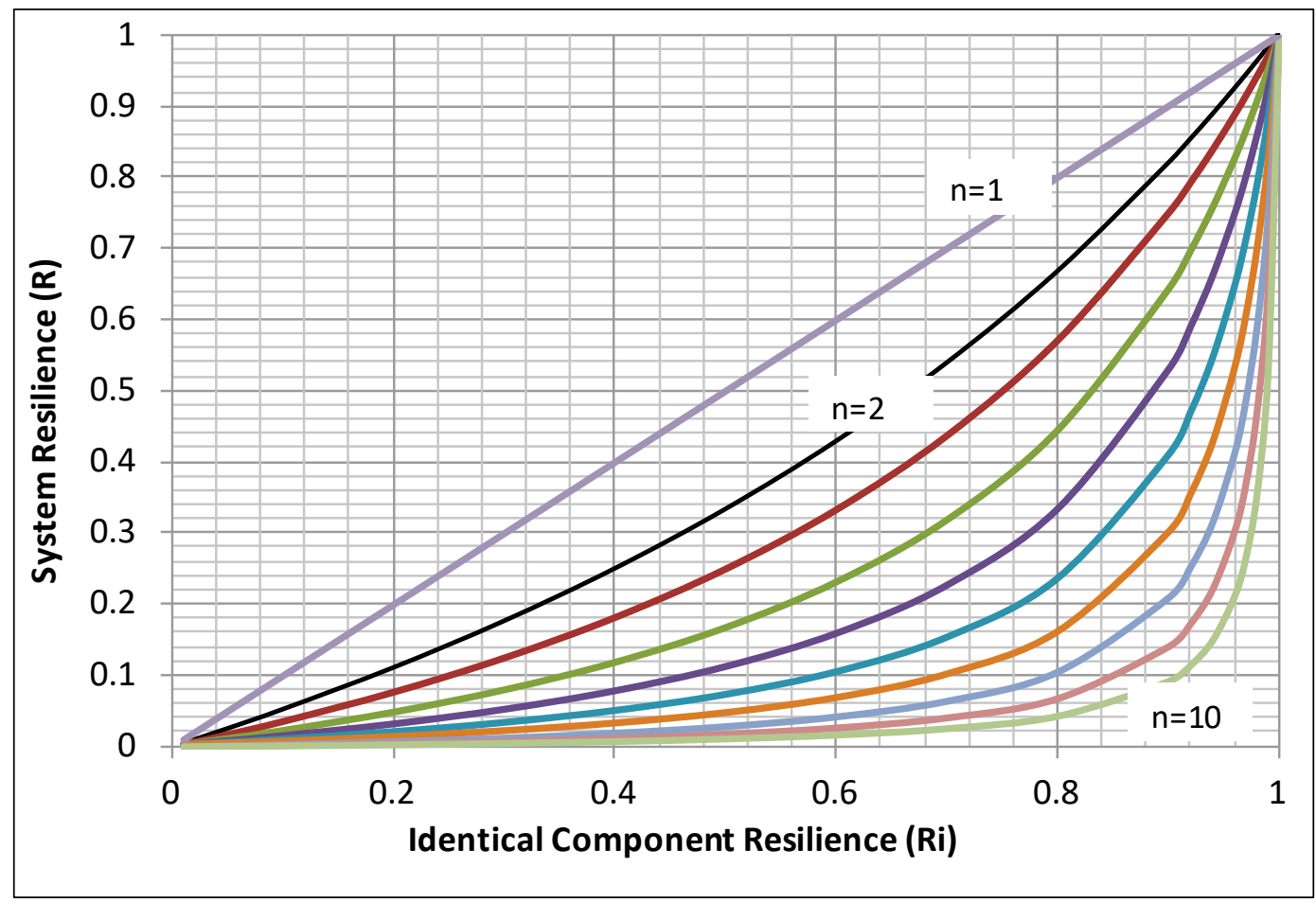

\subsubsection{Decision alternatives}

Managing resilience requires the development of decision choices that could be constructed using decision tables. These decision alternatives could also build on needs to manage risk and address system vulnerabilities. In this context, risk can be defined as the potential losses resulting from an exposure to a risk event or hazards, and a vulnerability is defined as the intrinsic properties of a system making it susceptible to a hazard or a threat. Other considerations in decision making may include the following:

- Critical links (weakest links) for best investment (efficient use of resources)

- Timing and time to address the situation

- Ownerships: Features on government land versus owned by a community

- Economics of resilience

- Legal and liability considerations

- Finance related considerations. 


\subsubsection{Resilience and sustainability}

\subsubsection{Relationship}

The ASCE defines sustainability, in its Policy Statement 418 (ASCE 2016), as a "set of economic, environmental and social conditions in which all of society has the capacity and opportunity to maintain and improve its quality of life indefinitely, without degrading the quantity, quality or the availability of natural, economic and social resources." Sustainable development is the application of these resources to enhance the safety, welfare, and quality of life for all of society. Several other definitions are available as provided by Webb and Ayyub (2016) in Table 8.

Table 8. Selected sustainability definitions (adapted after Webb and Ayyub 2016).

\begin{tabular}{|c|c|}
\hline Context & Definition and Source \\
\hline General & $\begin{array}{l}\text { "Creating and maintaining conditions under which humans and } \\
\text { nature can exist in productive harmony and that permit fulfilling } \\
\text { social, economic, and other requirements of present and future } \\
\text { generations." (EPA 2016a) } \\
\text { "Ability to maintain or improve standards of living without damaging or } \\
\text { depleting natural resources for present and future generations." (EPA } \\
\text { 2016b) }\end{array}$ \\
\hline Manufacturing & $\begin{array}{l}\text { "The creation of manufactured products that use processes that } \\
\text { minimize negative environmental impacts, conserve energy and } \\
\text { natural resources, are safe for employees, communities, and } \\
\text { consumers and are economically sound." (ITA 2016) }\end{array}$ \\
\hline Green buildings & $\begin{array}{l}\text { "The practice of increasing the efficiency with which buildings and } \\
\text { their sites use and harvest energy, water, and materials; and } \\
\text { protecting and restoring human health and the environment, } \\
\text { throughout the building life-cycle: siting, design, construction, } \\
\text { operation, maintenance, renovation and deconstruction." (EPA 2016c) }\end{array}$ \\
\hline
\end{tabular}

Redman (2014) provides a discussion on contrasting elements of resilience and sustainability. A resilience theory approach recognizes the following:

- Change is normal with multiple stable states.

- Experience leads to a gracefully adaptive cycle.

- Resilience originates in ecology for maintaining ecosystem services.

- Results of change are open ended and emergent.

- Resilience is concerned with maintaining system dynamics.

- Stakeholder input is focused on desirable dynamics.

Conversely, a sustainability science approach recognizes the following: 
- This approach envisions the future and acts to make it happen.

- It utilizes transition management approach.

- It originates in social sciences with the presumption that a society is flawed.

- Its desired results of change are specified in advance.

- Its focus is on interventions that lead to sustainability.

- Stakeholder input is focused on desirable outcomes.

Redman's sustainability science approach is descriptive on how an engineer addresses both sustainability and resilience where resilience is treated as an aspect of sustainability during the lifecycle of a project or in the management of a system, enterprise, or community. The lifecycle includes conception, design, construction, operation, maintenance, and renewal or removal. The necessary steps are the following:

- Envision the future, for normal function and response to a perturbation, and act for sustainability and resilience.

- Use a transition management approach from current to desired conditions.

- Seek desired results of change that are specified in advance.

- Focus on interventions that lead to sustainability and resilience.

- Seek stakeholder input by focusing on desired outcomes.

According to Ayyub and Wright (2016), the following precepts should be captured in relating resilience and sustainability:

1. Systems that are resilient might not be sustainable.

2. Systems that are not resilient are not sustainable.

3. Systems that are not sustainable might be resilient.

\section{$\underline{\text { Definitions }}$}

- $\mathrm{R}=$ resilient infrastructure systems (with $\underline{\mathrm{R}}=$ non-resilient infrastructure systems)

- $\mathrm{S}=$ sustainable infrastructure systems (with $\underline{\mathrm{S}}=$ non-sustainable infrastructure systems)

Using a Venn diagram (Figure 17) of two ovals representing resilient and sustainable infrastructure systems within a rectangular sample space set, the following cases were considered: 
- Case 1. R and S are mutually exclusive.

- Case 2. R and S are independent.

- Case 3. R and S are with positive dependency.

- Case 4. R and S are with negative dependency.

- Case 5. R and S are perfectly dependent with R nested in S.

- Case 6. R and $\mathrm{S}$ are perfectly dependent with $\mathrm{S}$ nested in R.

Figure 17. Case 6 where $R$ and S are perfectly dependent with $S$ nested in $R$.

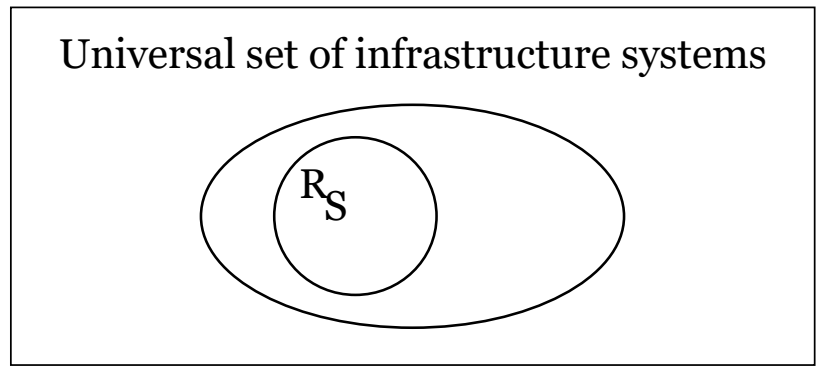

The most general cases are 2, 3, and 4, whereas the most appropriate representation of infrastructure systems is Case 6. Case 6, as shown in Figure 17, is consistent with the above three precepts. The figure basically states that generally sustainable infrastructure systems are a subset of resilient infrastructure systems.

\subsubsection{Quantification and economics of resilience and sustainability}

It is desirable to quantify resilience and sustainability in an axiomatically consistent manner using methods that are based on appropriate definitions of resilience and sustainability. These definitions would offer bases for defining requirements for quantification methods, followed by using or developing quantification methods to meet these requirements. The quantification methods and metrics should retain in its results uncertainty estimates and should offer a basis for economic valuation.

\subsubsection{Resilience, sustainability, and asset management}

Estimating the economic burden of disasters requires appropriate models that account for key characteristics and decision-making needs (Gilbert and Ayyub 2016). Enhancing system resilience and sustainability could lead to significant savings through risk reduction and expeditious recovery. The management of such reduction and recovery is facilitated by an appropriate definition of resilience and associated metrics with models for examining the economics of resilience and sustainability. Gilbert and 
Ayyub (2016) provide such microeconomic models, compare them, examine their sensitivities to key parameters, and illustrate their uses. Note that these models are useful as well for asset management and will be considered in future resilience studies. 


\section{References}

American Society of Civil Engineers (ASCE). 2016. Policy Statement 418: The Role of the Civil Engineer in Sustainable Development. Accessed February 9. http://www.asce.org/issues-and-advocacy/public-policy/policy-statement-418---the-role-of-thecivil-engineer-in-sustainable-development/

ASCE. 2013. Policy Statement 518. Accessed June 25. https://www.asce.org/issues-andadvocacy/public-policy/policy-statement-518---unified-definitions-for-critical-infrastructureresilience/

Attoh-Okine, N., A. T. Cooper, and S. A. Mensah. 2009, "Formulation of Resilience Index of Urban Infrastructure Using Belief Functions." IEEE Systems Journal 3(2): 147-153.

Ayyub B. M., H. G. Braileanu, and N. Qureshi. 2012. "Prediction and Impact of Sea Level Rise on Properties and Infrastructure of Washington, DC.” J. Risk Analysis 32(11): 1901-1918.

Ayyub, B. M. 2014a. "Systems Resilience for Multihazard Environments: Definition, Metrics, and Valuation for Decision Making." J. Risk Analysis 34(2): 340-355.

Ayyub, B. M. 2014b. Risk Analysis in Engineering and Economics, Second Edition. Boca Raton, FL: Chapman \& Hall/CRC, Taylor \& Francis Group.

Ayyub, B. M., J. Foster, and W. L. McGill. 2009a. "Risk Analysis of a Protected Hurricane-Prone Region I: Model Development.” ASCE Natural Hazards Review 10(2): 38-53. https://ascelibrary.org/doi/full/10.1061/\%28ASCE\%2915276988\%282009\%2910\%3A2\%2854\%29

Ayyub, B. M., W. L. McGill, J. Foster, and H. W. Jones. 2009b. "Risk Analysis of a Protected Hurricane-Prone Region II: Computations and Illustrations.” ASCE Natural Hazards Review 10(2): 54-67. https://ascelibrary.org/doi/full/10.1061/\%28ASCE\%2915276988\%282009\%2910\%3A2\%2854\%29

Ayyub, B. 2015. "Practical Resilience Metrics for Planning, Design and Decision Making." ASCE-ASME J. Risk Uncertainty Eng. Syst., Part A: Civil Eng. 1(3). https://doi.org/10.1061/AJRUA6.0000826

Ayyub, B. M., and R. N. Wright. 2016. "Adaptive Climate Risk Control of Sustainability and Resilience for Infrastructure Systems.” J. Geography and Natural Disasters 6(2). http://dx.doi.org/10.4172/2167-0587.1000e118

Barras, J. 2007. Satellite Images and Aerial Photographs of the Effects of Hurricanes Katrina and Rita on Coastal Louisiana. USGS, Data Series 281, Version 1.o. https://pubs.usgs.gov/ds/2007/281/

Becker, G. S., T. J. Philipson, and R. R. Soares. 2005. "The Quantity and Quality of Life and the Evolution of World Inequality." American Economic Review 95(1): 277291. https://www.aeaweb.org/articles?id=10.1257/0002828053828563 
Bonstrom, H., and R. B. Corotis. 2014. "First-Order Reliability Approach to Quantify and Improve Building Portfolio Resilience." J. of Structural Engineering, ASCE $142(8)$.

Bridges, T. S., P. W. Wagner, K. A. Burks-Copes, M. E. Bates, Z. A. Collier, C. J. Fischenich, J. Z. Gailani, L. D. Leuck, C. D. Piercy, J. D. Rosati, E. J. Russo, D. J. Shafer, B. C. Suedel, E. A. Vuxton, and T. V. Wamsley. 2015. Use of Natural and Nature-Based Features (NNBF) for Coastal Resilience. ERDC SR-15-1.

Vicksburg, MS: U.S. Army Engineer Research and Development Center.

Bruneau M., and A. Reinhorn. 2007. "Exploring the Concept of Seismic Resilience for Acute Care Facilities." Earthquake Spectra 23(1): 41-62.

Bureau of Economic Analysis (BEA). 2014. Washington, DC: U.S. Department of Commerce. Accessed 5 March 2019). http://www.bea.gov/data

Cable News Network (CNN). "Hurricane Katrina Statistics Fast Facts." CNN Library. Cable News Network. 23 August 2016. Web. 01 May 2015. Article updated 20 August 2018. https://www.cnn.com/2013/08/23/us/hurricane-katrina-statistics-fastfacts/index.html

Chang, S. E., and M. Shinozuka. 2004. "Measuring Improvements in the Disaster Resilience of Communities." Earthquake Spectra 20(3): 739-755.

Cimellaro, G. P., A. M. Reinhorn, and M. Bruneau. 2010. "Seismic Resilience of a Hospital System.” Structure and Infrastructure Engineering 6(1-2): 127-144.

Cimellaro, G. P., C. Renschler, A. M. Reinhorn, and L. Arendt. 2016. "PEOPLES: A Framework for Evaluating Resilience.” J. Structural Engineering, ASCE 142(10). https://ascelibrary.org/doi/full/10.1061/\%28ASCE\%29ST.1943-541X.0001514

Civil Contingencies Secretariat of the Cabinet Office, London, UK. 2003. Accessed 5 March 2019. www.cabinetoffice.gov.uk

Cox, Jr., L. A. 2012. "Community Resilience and Decision Theory Challenges for Catastrophic Risk.” Risk Analysis 32(11): 1919-1934. https://doi.org/10.1111/j.15396924.2012.01881.x

Cunniff, S., and A. Schwartz. 2015. Performance of Natural Infrastructure and Naturebased Measures as Coastal Risk Reduction Features. Environmental Defense Fund.

https://www.cakex.org/sites/default/files/documents/Performance\%20of\%20Natural\%20Infra structure\%20and\%20Naturebased\%20Measures\%20as\%20Coastal\%20Risk\%20Reduction\%20Features.pdf

Cutter, S. L. 2008. A Framework for Measuring Coastal Hazard Resilience in New Jersey Communities. White paper prepared for the Urban Coast Institute at Monmouth University. https://www.monmouth.edu/uploadedFiles/Resources/Urban_Coast_Institute/SusanCutterFra meworkforMeasuringCoastalHazardResilientCommun.pdf (accessed on April 28, 2016.)

Department of Homeland Security (DHS). 2008. DHS Risk Lexicon. Risk Steering Committee. U.S. Department of Homeland Security. www.dhs.gov/xlibrary/assets/dhs_risk_lexicon.pdf 
Department of the Interior (DOI). 2015. Recommendations for Assessing the Effects of the DOI Hurricane Sandy Mitigation and Resilience Program on Ecological System and Infrastructure Resilience in the Northeast Coastal Region. Department of the Interior Metrics Expert Group. https://www.doi.gov/sites/doi.gov/files/migrated/news/upload/Hurricane-Sandy-projectmetrics-report.pdf

Dunkin, L. 2016. National Coastal Mapping Program: Volume Change ArcGIS Toolbox. U. S. Army Corps of Engineers. Accessed April 21. http://rsm.usace.army.mil/techtransfer/meetings/RPATWebinar2014/RPAT_Webinar_20140813.pdf

Ellingwood, B. R., and Y. Mori. 1993. "Probabilistic Methods for Condition Assessment and Life Prediction of Concrete Structures in Nuclear Plants." Nuclear Engineering and Design 142(2-3): 155-166.

Environmental Protection Agency (EPA). 2016a. Learn About Sustainability. Accessed April 21. https://www.epa.gov/sustainability/learn-about-sustainability

EPA. 2016b. EPA's Report on the Environment. Accessed April 21. https://cfpub.epa.gov/roe/

EPA. 2016c. Green Buildings. Accessed April 21. https://archive.epa.gov/greenbuilding/web/html/

Federal Emergency Management Agency (FEMA). 2016. "Hurricane Katrina." Hurricane Katrina. Washington, DC: Department of Homeland Security. 01 December 2016. http:/www.FEMA.gov

Fox-Lent, C., M. Bates, and I. Linkov. 2105. "A Matrix Approach to Community Resilience Assessment: an Illustrative Case at Rockaway Peninsula." Environ Syst Decis 35(2): 209-218. https://doi.org/10.1007/s10669-015-9555-4

Garbin, D. A., and J. F. Shortle. 2007. "Measuring Resilience in Network-Based Infrastructures." Critical Thinking: Moving from Infrastructure Protection to Infrastructure Resiliency. Edited by J. A. McCarthy, 73-86. George Mason University, VA.

Gilbert, S. W. 2010. Disaster Resilience: A Guide to the Literature. NIST Special Publication 1117. Gaithersburg, MD: Office of Applied Economics, Building and Fire Research Laboratory, National Institute of Standards and Technology. https://nvlpubs.nist.gov/nistpubs/Legacy/SP/nistspecialpublication1117.pdf

Gilbert, S., and B. Ayyub. 2016. "Models for the Economics of Resilience." ASCE-ASME J. Risk Uncertainty Eng. Syst., Part A: Civil Eng. 2(4). https://doi.org/10.1061/AJRUA6.0000867

Gravens, M., B. Ebersole, T. Walton, and R. Wise. 2014. Beach Fill Design. EM 1110-21100. Part 5. Washington, DC: U.S. Army Corps of Engineers.

Hapke, C. J., O. T. Brenner, and R. E. Henderson. 2016. "Quantifying the Geomorphic Resiliency of Barrier Island Beaches.” Proceedings of the Coastal Sediments, May 11-15, 2015, San Diego, CA. 
Hashimoto, T., J. R. Stedinger, and D. P. Loucks. 1982. "Reliability, Resiliency and Vulnerability Criteria for Water Resources System Performance Evaluation.” Water Resource Res. 18(1): 14-20.

Holling, C. S. 1973. "Resilience and Stability of Ecological Systems." Annual Review of Ecology and Systematics 4: 1-23. https://doi.org/10.1146/annurev.es.04.110173.000245

Huang, W. P., and J. Z. Yim. 2014. "Sand Dune Restoration Experiments at Bei-Men Coast, Taiwan.” Ecological Engineering 73 (2014): 409-420.

Huntsman, S. R. 2011. "Design and Construction of the Lake Borgne Surge Barrier in Response to Hurricane Katrina." Conference on Coastal Engineering Practice 201108/2011. https://doi.org/10.1061/41190(422)11

International Organization of Standardizations (ISO). 2009. Risk Management - Risk Assessment Techniques. ISO Standard IEC/FDIS 31010, iso.org, Geneva: Switzerland.

International Trade Administration, Department of Commerce. 2016. How does Commerce Define Sustainable Manufacturing?

Kafali, C., and M. Grigoriu. 2005. "Rehabilitation Decision Analysis.” ICOSSAR'O5 Proceedings of the Ninth International Conference on Structural Safety and Reliability, 10-23 June, Rome, Italy.

Keeney, R. L., and R. S. Gregory. 2005. "Selecting Attributes to Measure the Achievement of Objectives.” Operations Research Informs 53(1): 1-11.

Li, Y., and B. Lence. 2007. "Estimating Resilience of Water Resources Systems." Water Resources 43(7): Wo7422.

Linkov I., D. A. Eisenberg, M. E. Bates, D. Chang, M. Convertino, J. H. Allen, S. E. Flynn, and T. P. Seager. 2013. "Measurable Resilience for Actionable Policy." Environ Sci Technol 47(18): 10103-10110. doi:10.1021/es403443n

McGill, W. L., and B. M. Ayyub. 2009. "Regional Capabilities Performance Assessment for Homeland Security.” IEEE Systems J. 3(2): 192-198.

McKay, K., I. Linkov, J. C. Fischenich, S. J. Miller, and L. J. Valverde, Jr. 2012. Ecosystem Restoration Objectives and Metrics. ERDC TN-EMRRP-EBA-16. Washington, DC: U.S. Army Corps of Engineers. http://hdl.handle.net/11681/3930

Miles, S., and S. Chang. 2003. Urban Disaster Recovery: A Framework and Simulation Mode, MCEER. Buffalo, NY: Multidisciplinary Center for Earthquake Engineering Research (MCEER) of the State University of New York at Buffalo.

National Infrastructure Advisory Council. 2009. Critical Infrastructure Resilience Final Report and Recommendations. https://www.dhs.gov/xlibrary/assets/niac/niac_critical_infrastructure_resilience.pdf 
National Oceanic and Atmospheric Administration (NOAA). 2016. The National Coastal Population Report: Populations Trends from 1970 to 2020. Issued in partnership with the U.S. Census Bureau; updates and expands a 2004 report that detailed and projected coastal population trends from 1980 to 2008. Accessed April 19. https://coast.noaa.gov/digitalcoast/training/population-report.html

National Research Council (NRC). 1996. Measuring and Improving Infrastructure Performance, Committee on Measuring and Improving Infrastructure Performance. ISBN: 0-309-58710-7. Washington, DC: The National Academies Press.

NRC. 2011. National Earthquake Resilience: Research, Implementation, and Outreach. Washington, DC: National Academies Press.

NRC. 2012. Disaster Resilience: A National Imperative. Washington, DC: National Academies Press.

Nordstrom, K. F. 2000. Beaches and Dunes of Developed Coasts. Cambridge, UK: Cambridge University Press.

Nordstrom, K. F. 2009. Beach and Dune Restoration. New York: Cambridge University Press.

Omer, M., R. Nilchiani, and A. Mostashari. 2009. "Measuring the Resilience of the Global Internet Infrastructure System.” 2009 3rd Annual Systems Conference, IEEE, 156-162.

Presidential Policy Directive (PPD). Critical Infrastructure Security and Resilience. PPD21. Released February 12, 2013. http://www.whitehouse.gov/the-pressoffice/2013/02/12/presidential-policy-directive-critical-infrastructure-security-and-resil

PPD. National Preparedness. PPD-8. Released March 30, 2011. http://www.dhs.gov/xabout/laws/gc_1215444247124.shtm

Redman, C. L. 2014. "Should Sustainability and Resilience Be Combined or Remain Distinct Pursuits?” Ecology and Society 19(2): 37. http://dx.doi.org/10.5751/ES$\underline{06390-190237}$

Renschler, C. S., A. E. Frazier, L. A. Arendt, G.-P. Cimellaro, A. M Reinhorn, and M. Bruneau. 2010. A Framework for Defining and Measuring Resilience at the Community Scale: The PEOPLES Resilience Framework. TR MCEER-10-00o6. Buffalo, NY: Multidisciplinary Center for Earthquake Engineering Research (MCEER) of the State University of New York at Buffalo. https://ubir.buffalo.edu/xmlui/bitstream/handle/10477/25353/10-0006.pdf

Rosati, J. D., K. F. Touzinsky, and W. F. Lillycrop. 2015. "Quantifying Coastal System Resilience for the U.S. Army Corps of Engineers.” Environ Syst Decis 35(2): 196208. https://link.springer.com/article/10.1007/s10669-015-9548-3

Schultz, M. T., S. K. McKay, and L. Z. Hales. 2012. The Quantification and Evolution of Resilience in Integrated Coastal Systems. ERDC TR-12-7. Vicksburg, MS: U.S. Army Engineer Research and Development Center. https://apps.dtic.mil/dtic/tr/fulltext/u2/a570387.pdf 
Shinozuka, M., S. E. Chang, T. -C. Cheng, M. Feng, T. D. O’Rourke, M. A. Saadeghvaziri, X. Dong, X. Jin, Y. Wang, and P. Shi. 2004. "Resilience of Integrated Power and Water Systems." MCEER Research Progress and Accomplishments: 2003-2004. MCEER-04-SPO1. NY.

Subcommittee on Disaster Reduction (SDR). 2005. Grand Challenges for Disaster Reduction. Washington, DC: National Science and Technology Council.

Tierney, K., and M. Bruneau. 2007. Conceptualized and Measuring Resilience. TR News 250, 14-17. http://onlinepubs.trb.org/onlinepubs/trnews/trnews250_p14-17.pdf

United Nations International Strategy for Disaster Reduction (UNISDR). 2012. Making Cities Resilient: My City is Getting Ready! A Global Snapshot of How Local Governments Reduce Disaster Risk. United Nations Office for Disaster Risk Reduction Report, Geneva, Switzerland. www.unisdr.org/campaign

UNISDR. 2005. Hyogo Framework for Action 2005-2015: Building the Resilience of Nations and Communities to Disasters. Geneva, Switzerland. http://www.unisdr.org/2005/wcdr/intergover/official-doc/L-docs/Hyogo-framework-for-actionenglish.pdf

U.S. Army Corps of Engineers (USACE). 2006. Performance Evaluation of the New Orleans and Southeast Louisiana Hurricane Protection System, the Interagency Performance Evaluation Task Force. Vol. I - Executive Summary and Overview. Washington, DC.

USACE. 2013a. Hurricane Sandy Coastal Projects Performance Evaluation Study Disaster Relief Appropriations Act, 2013. Report Submitted by the Assistant Secretary of the Army for Civil Works on November 6, 2013. Washington, DC.

USACE. 2013b. Coastal Risk Reduction and Resilience: Using the Full Array of Measures. CWTS 2013-3. U.S. Army Corps of Engineers, Directorate of Civil Works, Washington, DC. https://usace.contentdm.oclc.org/digital/collection/p266001coll1/id/5270

Urban Land Institute (ULI). 2013. Risk and Resilience in Coastal Regions: A ULI Global Policy and Practice Forum Report. Washington, DC. http://uli.org/wpcontent/uploads/ULI-Documents/CoastalRegions.pdf

Wamsley, T. V., Z. A. Collier, K. Brodie, L. M. Dunkin, D. Ruff, and J. D. Rosati. 2015. "Guidance for Developing Coastal Vulnerability Metrics." J. Coastal Research 31(6): 1521-1530.

Webb, D., and B. M. Ayyub. 2016. "Sustainable Construction and Manufacturing: Definitions, Metrics and Valuations for Decision Making." ASCE-ASME J. Risk Uncertainty Eng. Syst., Part A: Civ. Eng. 3(3).

White House, Office of the Press Secretary. 2013. Executive Order 13653: "Preparing the U.S. for Climate Change." Washington, DC. https://obamawhitehouse.archives.gov/the-press-office/2013/11/01/executive-orderpreparing-united-states-impacts-climate-change 
World Economic Forum. 2011. Global Risks, Sixth Edition, World Economic Forum. In collaboration with Marsh \& McLennan Companies, Swiss Reinsurance Company, Wharton Center for Risk Management, University of Pennsylvania, and Zurich Financial Services, Geneva, Switzerland. https://www.weforum.org/reports/global-risksreport-2011/ 


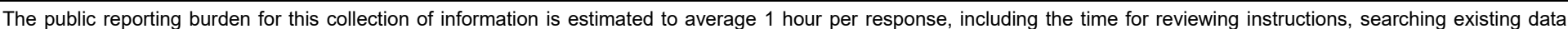

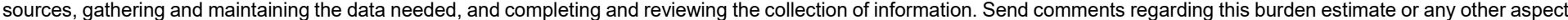

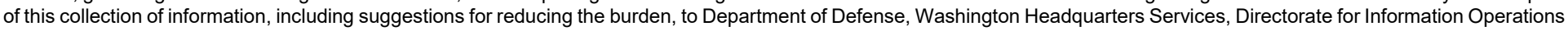

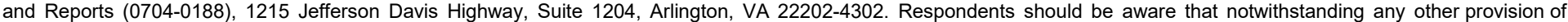
law, no person shall be subject to any penalty for failing to comply with a collection of information if it does not display a currently valid OMB control number.

PLEASE DO NOT RETURN YOUR FORM TO THE ABOVE ADDRESS.
1. REPORT DATE
May 2019
2. REPORT TYPE
3. DATES COVERED (From - To)
Final Report

4. TITLE AND SUBTITLE

Practical Resilience Metrics for Coastal Infrastructure Features

5a. CONTRACT NUMBER

5b. GRANT NUMBER

5c. PROGRAM ELEMENT NUMBER

6. AUTHOR(S)

5d. PROJECT NUMBER

454623

Bilal M. Ayyub

5e. TASK NUMBER

5f. WORK UNIT NUMBER

8. PERFORMING

ORGANIZATION REPORT

NUMBER

BMA Engineering, Inc. (BMA)

11429 Palatine Drive

ERDC/CHL CR-19-1

Potomac, MD 20854

9. SPONSORING/MONITORING AGENCY NAME(S) AND ADDRESS(ES)

U.S. Army Corps of Engineers

10. SPONSOR/MONITOR'S ACRONYM(S)

USACE

Washington, DC 20314-1000

11. SPONSOR/MONITOR'S

REPORT NUMBER(S)

\section{DISTRIBUTION/AVAILABILITY STATEMENT}

Approved for public release; distribution is unlimited.

\section{SUPPLEMENTARY NOTES}

14. ABSTRACT

This effort is directed towards improving basic understanding of the resilience of complex systems for the development of practical resilience metrics that quantify the capacity to withstand damages, rapidly recover, and adapt to future change. The resilience metrics are based on practical performance measures of coastal infrastructure.

Massive savings could be realized by enhancing the resilience of a system, including infrastructure, networks, and communities through risk reduction and expeditious recovery. Existing metrics do not always lend themselves easily and intuitively to practical applications in effective and efficient manners. The coastal and storm damage reduction, navigation, and environmental missions of the U.S. Army Corps of Engineers (USACE) require consistent, transparent, quantitative metrics with which to understand the resiliency of these complex systems.

This report provides a resilience definition that meets a set of requirements with clear relationships to metrics of the relevant abstract notions of reliability and risk. The report also provides metrics that are practical and simplified while capturing all the attribute set in the resilience definition. Recovery models with case studies, and illustrative examples, are also provided. Next steps are defined. The report contributes towards advancing the USACE capabilities in defining, quantifying, and assessing coastal and watershed system resilience.

\section{SUBJECT TERMS}

Coastal engineering, Resilience (Ecology)Natural disasters, Flood control, Statistics

\section{SECURITY CLASSIFICATION OF:}

\begin{tabular}{|l|c|c|r}
\hline a. REPORT & b. ABSTRACT & c. THIS PAGE & ABSTRACT \\
Unclassified & Unclassified & Unclassified & SAR \\
& & &
\end{tabular}

18. NUMBER OF PAGES

67 19a. NAME OF RESPONSIBLE PERSON

19b. TELEPHONE NUMBER (Include area code) 601-634-2006 